\title{
POLITICAL CONFLICT AND BARGAINING IN A NEW KEYNESIAN MODEL OF FISCAL STABILIZATION
}

\author{
Francesca Flamini and Campbell Leith \\ University of Glasgow
}

Recent work on optimal monetary and fiscal policy in New Keynesian models has tended to focus on policy set by an infinitely lived benevolent policy maker, often with access to a commitment technology. In this paper, we explore deviations from this ideal, by allowing (time-consistent) policy to be set by a process of bargaining between two political players with different weights on elements of the social welfare function. We characterize the (linear) Markov perfect equilibrium and, in a series of numerical examples, we explore the resultant policy response to shocks which cannot be perfectly offset with the available instruments due to their fiscal consequences. We find that, even although the players, on average, have the socially desirable objective function, the process of bargaining implies an outcome which deviates from the time-consistent policy chosen by the benevolent policy maker. Moreover, the range of instruments available mean that policy makers will bargain across the entire policy mix, sometimes implying outcomes which are quite different from those that would be chosen by a single policy maker. These policy outcomes depend crucially on the nature of the conflict and also the level of government debt.

Keywords: New Keynesian Model, Government Debt, Monetary Policy, Fiscal Policy, Bargaining, Investment, Recursive Optimization, Markov Perfect Equilibrium

\section{INTRODUCTION}

Work on optimal monetary and fiscal policy in New Keynesian models has tended to focus on policy set by an infinitely lived benevolent policy maker, often with access to a commitment technology. ${ }^{1}$ If the ideal of a single policy maker implementing a Ramsey plan is relaxed, this tends to be done in two possible ways. First, the literature has dropped the assumption that the policy maker is able to commit and considered the case of time-consistent policy-making. ${ }^{2}$ Second, some papers have also introduced multiple policy makers by allowing an independent central bank $(\mathrm{CB})$ to interact with a government setting fiscal policy. ${ }^{3}$ 
In this paper, we further explore deviations from the ideal of a benevolent policy maker with access to a commitment technology, by allowing policy to be set by a process of bargaining between two players with different attitudes toward the appropriate weights on elements of the social welfare function. The exact definition of these "players" is quite flexible. The simplest interpretation is of two political parties operating as a coalition government, but it can also encompass conflict between branches of the legislature; a minority government and the opposition; ministries within a majority government; and even conflict between a government and delegated policy-making institution such as an independent CB. These players, then, alternate in making proposals over the policy mix (consisting of monetary policy and tax and government spending levels) until agreement is reached and policy implemented. The key difference between this approach and the typical analysis of strategic conflict between a government and an independent $\mathrm{CB}$ is that our approach focuses on bargained policy outcomes rather than strategic interactions between two players with separate control over a subset of policy instruments. This enables our approach to capture a wider range of conflicting policy maker objectives and reflect the reality that policy typically emerges as a result of the interactions of many actors. ${ }^{4,5}$

In terms of modeling, we extend the dynamic bargaining game of Flamini (2012) to the case of an infinite number of bargaining stages and embed it in a New Keynesian Dynamic Stochastic General Equilibrium (DSGE) model. In the model economy, households supply labor to imperfectly competitive firms who are only able to adjust prices after random intervals of time (as in Calvo (1983)). We construct a social welfare measure based on the utility of the households populating this economy. The policy instruments available to policy makers are interest rates, an income tax, and government expenditure. In the absence of a government financing constraint, this would be a sufficient array of instruments to achieve the first best allocation. However, aside from any frictions caused by the presence of bargaining, policy makers need to balance the desire to offset the costs of shocks in a sticky price environment against the need to satisfy their intertemporal budget constraint. This is clearly of relevance given the number of countries who grappled with both rising unemployment and government debt following the recent credit crunch. The use of a wide range of policy instruments, aside from being realistic, also implies that there can be many dimensions along which compromises can be made in reaching agreement over the policy mix.

We show that the use of the various instruments to stabilize debt following shocks can be very different with and without bargaining. In a series of examples, we focus on conflict over the relative importance of stabilizing inflation, government spending, and private consumption, respectively, during the period of fiscal adjustment. ${ }^{6}$ In the absence of bargaining, and in the presence of a positive shock to debt, government spending falls. The remainder of the policy mix depends, crucially, on the level of debt since this affects the relative efficacy of alternative policy instruments. At lower debt levels, spending cuts are accompanied by tax rises and a tightening of monetary policy to moderate inflation. At higher debt 
levels, monetary policy becomes a far more effective means of stabilizing debt, and interest rates are cut to boost the tax base and reduce debt service costs. In this case, tax rates may actually fall to mitigate the rise in inflation caused by the relaxation of monetary policy.

The policy outcomes can be quite different in the presence of bargaining, with parties possessing different degrees of aversion to the use of a particular instrument/policy objective relative to other elements in the welfare function (although on average policy makers' preferences mirror those of society).

When conflict is over the degree of inflation conservatism, typically the policy maker who is less averse to inflation will be able to achieve a bargained outcome closer to his preferences, especially as debt levels rise. This is due to the fact that inflation is such an effective means of reducing debt that she will be able to compensate the other policy maker with favorable movements in other welfare-relevant variables. When the conflict is over the stabilization of public consumption, the nature of the concessions depends crucially on the level of debt. At low debt levels, government spending is a relatively effective policy instrument and the policy maker who wishes to encourage its use can achieve agreement by reducing the adjustment required in other welfare-relevant variables. At higher debt levels, this is not the case, and the policy maker who wishes to rely less heavily on spending cuts achieves this in the bargained policy outcome. Finally, when conflict is over the volatility of private consumption (which, indirectly, is a proxy for the use of monetary policy as a stabilization device), we find that bargaining always reduces the reliance on this instrument, although, whether it is tax or inflation which takes up the slack, depends on whether debt levels are low or high, respectively.

Introducing an inflation-averse independent $\mathrm{CB}$ implies a tighter monetary policy in the face of fiscal shocks such that inflation is lower for a given level of debt. The moderation of inflation reduces the incentives of the fiscal players to agree a rapid correction of debt. This is quite different from the case of bargained policy outcomes - the less inflation-averse player is able to extract concessions from the other player due to the relative efficacy of surprise inflation as a device to stabilize debt, raising the speed of fiscal correction. Therefore, policy resulting from strategic interactions between policy makers in control of specific instruments can be quite different from bargained policy outcomes, as the latter takes account of the costs and benefits of alternative policies for one's opponents when attempting to reach agreement.

Our paper also touches on a number of additional literatures. Firstly, analyses of the interaction between coalition politics and fiscal policy have typically focused on the possibility of a deficit bias, due to either a common pool problem, where multiple policy makers do not internalize the full costs of their spending decisions (see, e.g., Velasco (2000)) or a war of attrition (see Alesina and Drazen (1991), Drazen and Grilli (1993), Spolaore (2004), and Martinelli and Escorza (2007)), where fiscal consolidations are delayed as political factions battle over who shall bear the costs. ${ }^{7}$ Unlike our paper, which employs a sticky price economy, these 
models do not include a macroeconomic stabilization role for fiscal policy, but instead focus on real economies requiring fiscal consolidation. Secondly, our paper extends the literature on dynamic bargaining. Although such a dynamic element is a typical feature of many long-run negotiations, within Game Theory, these have rarely been investigated. Recent exceptions are Sorger (2006), within a cooperative framework, and Flamini (2012), within a noncooperative framework. Finally, there is an extensive literature on public goods provision, where that provision can be subject to bargaining between players. See, for example, Bowen et al. (2014) which investigates two parties who have to decide over public spending under a simple bargaining procedure (take-it-or-leave-it) with the crucial feature that in disagreement they either spend nothing ("discretionary spending") or must implement the previous year's budget ("mandatory spending"). Hence, the status quo which emerges in the absence of agreement is endogenous in the latter.

Embedding a dynamic bargaining framework within a DSGE model, as we do, is even richer than such analyses. This complexity arises in three ways. Firstly, the macroeconomic outcomes that players care about depend not only on agreements reached today, but on expectations of the policies that will be agreed and implemented tomorrow. Secondly, the agreements reached today will affect the government debt stock inherited in the future which will affect the bargaining that takes place in the future. Finally, the agreed policies must also be time-consistent as we assume that the coalition government does not have access to a commitment technology which enables it to make promises it would subsequently wish to break.

The plan of the paper is as follows. In Section 2, we outline our model in which consumers supply labor to imperfectly competitive firms who are only able to change prices at random intervals of time. Workers' labor income is taxed, and the government consumes and issues debt. In Section 3, we derive a second-order approximation to welfare for these households and describe how individual policy maker preferences differ from this benchmark. In Section 4, we analyze the bargaining game and derive the Markov perfect equilibrium (MPE) policies. These, then, inform the simulation results in Section 5. Sections 6 and 7 explore two extensions: the introduction of an independent CB and non-separable preferences in private and public consumption, respectively. Section 8 concludes.

\section{THE MODEL}

This section outlines our model of the underlying economy. The model is a standard New Keynesian DSGE model, but augmented to include the government's budget constraint where government spending is financed by distortionary taxation and/or borrowing. This basic setup is similar to that in Benigno and Woodford (2004) and Schmitt-Grohe and Uribe (2004) but with some differences as detailed in Leith and Wren-Lewis (2013). Firstly, we allow the government to vary government spending in an optimal way, rather than simply treating 
government spending as an exogenous flow which must be financed. Secondly, we eliminate the usual inflationary bias caused by an inefficiently low level of steady-state output due to imperfect competition and distortionary taxes, by introducing a subsidy financed by lump-sum taxes. ${ }^{8}$ However, we do not allow further use of lump-sum taxes to finance government spending and ensure fiscal solvency following shocks, instead governments must adjust spending and/or income taxes to ensure fiscal sustainability. The use of this steady-state subsidy enables us to formulate a valid linear-quadratic problem with which to analyze time-consistent linear MPE strategies in a DSGE model where policy is conducted by a process of bargaining. The use of higher order perturbation methods in order to avoid the use of the subsidy is complicated by the need to identify the steady state of the solution to the nonlinear problem which depends upon derivatives of the value function (see, e.g., Klein et al. (2008) and Martin (2009)), while the use of global projection methods (see Heer and Maussner (2009) Chapter 6 for a discussion) in an economy where policy is implemented through a process of bargaining is beyond the scope of the current paper.

Next, we examine the households' problem, before turning to the firms' problem.

\subsection{Households}

There is a continuum of households of size one. We shall assume full asset markets, such that, through risk sharing, they will face the same budget constraint. As a result, the typical household will seek to maximize the following objective function

$$
E_{0} \sum_{t=0}^{\infty} \beta^{t} U\left(C_{t}, N_{t}, G_{t} ; \xi_{t}, \xi_{t}^{N}\right)
$$

where $C_{t}, G_{t}$, and $N_{t}$ are a consumption aggregate, a public goods aggregate, and labor supply, respectively, and $\beta$ is the discount factor, $\xi_{t}$ is a time-preference shock, $\xi_{t}^{N}$ is a labor supply shock. ${ }^{9}$

The consumption aggregate is defined as

$$
C_{t}=\left(\int_{0}^{1} C_{t}(j)^{\frac{\epsilon-1}{\epsilon}} d j\right)^{\frac{\epsilon}{\epsilon-1}}
$$

where $j$ denotes the good's type or variety. The public goods aggregate takes the same form

$$
G_{t}=\left(\int_{0}^{1} G_{t}(j)^{\frac{\epsilon-1}{\epsilon}} d j\right)^{\frac{\epsilon}{\epsilon-1}} .
$$

The elasticity of substitution between varieties, $\epsilon$, is larger than 1 . The budget constraint at time $t$ is given by

$$
\int_{0}^{1} P_{t}(j) C_{t}(j) d j+E_{t}\left(Q_{t, t+1} D_{t+1}\right)=\Pi_{t}+D_{t}+W_{t} N_{t}\left(1-\tau_{t}\right)-T_{t},
$$


where $P_{t}(j)$ is the price of variety $j, D_{t+1}$ is the nominal payoff of the portfolio held at the end of period $t, \Pi_{t}$ is the representative household's share of profits in the imperfectly competitive firms, $W_{t}$ are wages, $\tau_{t}$ is an wage income tax rate, and $T_{t}$ are lump-sum taxes. $Q_{t, t+1}$ is the stochastic discount factor for one-period-ahead payoffs.

Households must first decide how to allocate a given level of expenditure across the various goods that are available. They do so by adjusting the share of a particular good in their consumption bundle to exploit any relative price differences - this minimizes the costs of consumption. Optimization of expenditure for any individual good implies the demand function

$$
C_{t}(j)=\left(\frac{P_{t}(j)}{P_{t}}\right)^{-\epsilon} C_{t}
$$

where we have price indices given by

$$
P_{t}=\left(\int_{0}^{1} P_{t}(j)^{1-\epsilon} d j\right)^{\frac{1}{1-\epsilon}} .
$$

The budget constraint can therefore be rewritten as

$$
P_{t} C_{t}+E_{t}\left(Q_{t, t+1} D_{t+1}\right)=\Pi_{t}+D_{t}+W_{t} N_{t}\left(1-\tau_{t}\right)-T_{t},
$$

where $\int_{0}^{1} P_{t}(j) C_{t}(j) d j=P_{t} C_{t}$.

2.1.1. Households' problems. The first of the households' intertemporal problems involves allocating consumption expenditure across time. For tractability, assume that (1) takes the specific form

$$
E_{0} \sum_{t=0}^{\infty} \beta^{t}\left(\frac{C_{t}^{1-\sigma} \xi_{t}^{-\sigma}}{1-\sigma}+\chi \frac{G_{t}^{1-\sigma} \xi_{t}^{-\sigma}}{1-\sigma}-\frac{N_{t}^{1+\varphi} \xi_{t}^{-\sigma} \xi_{t}^{N}}{1+\varphi}\right) .
$$

We can then maximize utility subject to the budget constraint (3) to obtain the optimal allocation of consumption across time,

$$
\beta\left(\frac{C_{t}}{C_{t+1}}\right)^{\sigma}\left(\frac{\xi_{t}}{\xi_{t+1}}\right)^{\sigma}\left(\frac{P_{t}}{P_{t+1}}\right)=Q_{t, t+1} .
$$

Taking conditional expectations on both sides and rearranging gives

$$
\beta R_{t} E_{t}\left[\left(\frac{C_{t}}{C_{t+1}}\right)^{\sigma}\left(\frac{\xi_{t}}{\xi_{t+1}}\right)^{\sigma}\left(\frac{P_{t}}{P_{t+1}}\right)\right]=1,
$$

where $R_{t}=\frac{1}{E_{t}\left\{Q_{t, t+1}\right\}}$ is the gross return on a riskless one-period bond paying off a unit of currency in $t+1$. This is the familiar consumption Euler equation which implies that consumers are attempting to smooth consumption over time such that the marginal utility of consumption is equal across periods (after allowing for tilting due to interest rates differing from the households' rate of time preference). Household optimization implies a transversality condition that combined with the 
no-Ponzi condition yields

$$
\lim _{T \rightarrow \infty} E_{t} Q_{t, T} D_{T}=0 .
$$

A log-linearized version of (5) can be written as

$$
\widehat{C}_{t}+\widehat{\xi}_{t}=E_{t}\left(\widehat{C}_{t+1}+\widehat{\xi}_{t+1}\right)-\frac{1}{\sigma}\left(r_{t}-E_{t}\left(\pi_{t+1}\right)\right),
$$

where hatted variables denote percentage deviations from steady state, $r_{t}=R_{t}-\rho$ where $\rho=\frac{1}{\beta}-1$, and $\pi_{t}=p_{t}-p_{t-1}$ is price inflation.

The households' problem is to determine the optimal labor supply. The firstorder condition (FOC) for the labor supply decision is given by

$$
\left(1-\tau_{t}\right) w_{t}=N_{t}^{\varphi} C_{t}^{\sigma} \xi_{t}^{N},
$$

where the real wage is defined as, $w_{t} \equiv \frac{W_{t}}{P_{t}}$. Log-linearizing implies

$$
-\frac{\bar{\tau}}{1-\bar{\tau}} \widehat{\tau}_{t}+\widehat{w}_{t}=\varphi \widehat{N}_{t}+\sigma \widehat{C}_{t}+\widehat{\xi}_{t}^{N},
$$

where $\bar{\tau}$ indicates the steady-state value of tax rate. Generally, an overbar indicates the steady-state value of a variable.

\subsection{Allocation of Government Spending}

The allocation of government spending across goods is determined by minimizing total costs, $\int_{0}^{1} P_{t}(j) G_{t}(j) d j$. Given the form of the basket of public goods this implies

$$
G_{t}(j)=\left(\frac{P_{t}(j)}{P_{t}}\right)^{-\epsilon} G_{t}
$$

\subsection{Firms}

The production function is linear, so for firm $j$

$$
Y_{t}(j)=A_{t} N_{t}(j),
$$

where $a_{t}=\ln \left(A_{t}\right)$ is time-varying and stochastic. While the demand curve they face is given by

$$
Y_{t}(j)=\left(\frac{P_{t}(j)}{P_{t}}\right)^{-\epsilon} Y_{t}
$$

where $Y_{t}=\left[\int_{0}^{1} Y_{t}(j)^{\frac{\epsilon-1}{\epsilon}} d j\right]^{\frac{\epsilon}{\epsilon-1}}$. The objective function of the firm is given by

$$
\sum_{s=0}^{\infty}\left(\theta_{p}\right)^{s} Q_{t, t+s}\left[\frac{P_{t}(j)}{P_{t+s}} Y(j)_{t+s}-\frac{W_{t+s}}{P_{t+s}} \frac{Y(j)_{t+s}(1-\varkappa)}{A_{t}}\right],
$$


where $\theta_{p}$ is the probability that the firm is unable to change its price in a particular period, $\varkappa$ is an employment subsidy which can be used to eliminate the steady-state distortion associated with monopolistic competition and distortionary income taxes. Profit maximization then implies that firms that are able to change price in period $t$ will select the following price

$$
P_{t}^{*}=\frac{\sum_{s=0}^{\infty}\left(\theta_{p}\right)^{s} Q_{t, t+s}\left(\epsilon \frac{W_{t+s}}{P_{t+s}} P_{t+s}^{\epsilon} \frac{Y_{t+s}}{A_{t+s}}\right)}{\sum_{s=0}^{\infty}\left(\theta_{p}\right)^{s} Q_{t, t+s}\left[(\epsilon-1) P_{t+s}^{-1} P_{t+s}^{\epsilon} Y_{t+s}(1-\varkappa)\right]} .
$$

Leith and Wren-Lewis (2013) show that log-linearization of this pricing behavior implies a New Keynesian Phillips curve (NKPC) for price inflation which is given by

$$
\pi_{t}=\beta E_{t} \pi_{t+1}+\gamma\left(\widehat{m c}_{t}+\widehat{\mu}_{t}\right),
$$

where $\gamma=\frac{\left(1-\theta_{p} \beta\right)\left(1-\theta_{p}\right)}{\theta_{p}}, \widehat{m c}_{t}=-a_{t}+\widehat{w}_{t}$ indicates the real log-linearized marginal cost of production at $t$, and we introduce a markup shock, $\widehat{\mu}_{t}$, representing the temporary deviation of the desired markup from its steady-state value.

\subsection{Equilibrium}

Goods market clearing requires, for each $\operatorname{good} j$

$$
Y_{t}(j)=C_{t}(j)+G_{t}(j),
$$

which allows us to write

$$
Y_{t}=C_{t}+G_{t}
$$

\subsection{Government Budget Constraint}

Noting the equivalence between factor incomes and national output

$$
P_{t} Y_{t}=W_{t} N_{t}+\Pi_{t}-\varkappa W_{t} N_{t},
$$

and the definition of aggregate demand, we can map the consumer's flow budget constraint, (3), to that of the government as

$$
T_{t}+W_{t} N_{t}\left(\tau_{t}-\varkappa\right)+Q_{t, t+1} D_{t+1}=D_{t}+P_{t} G_{t},
$$

where the net value of the households' portfolio at time $t$ is $D_{t}=R_{t-1} B_{t-1}$ and where $B_{t-1}$ is the stock of government bonds at the end of period $t-1$ and $R_{t-1}$ is the risk-free nominal interest rate.

As discussed above, in order to focus on the time inconsistency problem associated with the introduction of debt and distortionary taxation to the New Keynesian model, we follow Rotemberg and Woodford (1997) and later authors and introduce a steady-state subsidy. This subsidy ensures the steady state is efficient by eliminating the distortions caused by distortionary taxation and imperfect competition in price setting, and thereby removes the usual desire on the part of policy 
makers to raise output above its natural level to compensate for these distortions. It is financed by lump-sum taxation. We shall assume that both the level of the subsidy and the associated level of lump-sum taxation cannot be altered from this steady-state level, so that any changes in the government's budget constraint have to be financed by changes in distortionary taxation, government spending, or debt service costs. ${ }^{10}$ This implies that $W_{t} N_{t} \varkappa=T_{t}$ in our economy at all points in time, allowing us to simplify the budget constraint to

$$
W_{t} N_{t} \tau_{t}+B_{t}=R_{t-1} B_{t-1}+P_{t} G_{t} .
$$

Defining real debt as $b_{t-1} \equiv \frac{B_{t-1} R_{t-1}}{P_{t-1}}$, this can be written in real terms as

$$
w_{t} N_{t} \tau_{t}+\frac{b_{t}}{R_{t}}=\frac{b_{t-1}}{\pi_{t}}+G_{t},
$$

and its steady state by

$$
\bar{b}=\frac{\bar{w} \bar{N} \bar{\tau}-\bar{G}}{1-\beta} .
$$

We can log-linearize the government's flow budget constraint around this steady state, and replacing the interest rate with the consumption Euler equation, (6), yields

$$
\begin{aligned}
\widehat{b}_{t-1}-\pi_{t}= & \beta\left[\widehat{b}_{t}-E_{t}\left(\pi_{t+1}+\sigma\left(\widehat{C}_{t+1}+\widehat{\xi}_{t+1}\right)\right)\right] \\
& +\sigma \beta\left(\widehat{C}_{t}+\widehat{\xi}_{t}\right)+\frac{\bar{w} \bar{N} \bar{\tau}}{\bar{b}}\left(\widehat{w}_{t}+\widehat{N}_{t}+\widehat{\tau}_{t}\right) \\
& -\frac{\bar{G}}{\bar{b}} \widehat{G}_{t} .
\end{aligned}
$$

Appendix A.1 defines the steady-state ratios contained in this log-linearization as a function of model parameters and the steady-state debt-GDP ratio.

\section{POLICY OBJECTIVES}

In order to derive a welfare function for policy analysis, we proceed in the following manner. Firstly, we consider the social planner's problem. In steady state, we then contrast this with the outcome under flexible prices in order to determine the level of the steady-state subsidy required to ensure the model's steady state is efficient. Finally, we construct a quadratic approximation to utility in our sticky price/distortionary tax economy which assesses the extent to which endogenous variables differ from the efficient equilibrium due to the nominal inertia, tax distortions, and bargaining over policy present in the model. We then recast our model in terms of the "gap" variables contained within our welfare metric. Finally, we describe and motivate how the two policy makers' objective functions differ from the social optimum. 


\subsection{The Social Planner's Problem}

The social planner is not constrained by the price mechanism and simply maximizes the representative household's utility, (4), subject to the technology, (7), and resource constraints, (9). This yields the following FOCs

$$
\begin{gathered}
\left(C_{t}^{*}\right)^{-\sigma}=\chi\left(G_{t}^{*}\right)^{-\sigma}, \\
\left(C_{t}^{*}\right)^{-\sigma}-Y_{t}^{* \varphi} A_{t}^{-(1+\varphi)} \xi_{t}^{N}=0,
\end{gathered}
$$

where we introduce the "**" superscript to denote the efficient level of that variable. These can be log-linearized around the efficient steady state and given the national accounting identity we obtain

$$
\widehat{Y}_{t}^{*}=\left(\frac{1+\varphi}{\sigma+\varphi}\right) a_{t}-\frac{1}{\sigma+\varphi} \widehat{\xi}_{t}^{N}
$$

and

$$
\widehat{Y}_{t}^{*}=\widehat{C}_{t}^{*}=\widehat{G}_{t}^{*}
$$

\subsection{Social Welfare}

Appendix A.1 derives the subsidy, $\varkappa$, required for the steady state of the flexible price equilibrium to be efficient. Given this subsidy, if the government implements its spending plans in line with the social planner's problem in steady state, then the flex price steady state is the same as the efficient output level. Appendix A.1 also defines the steady-state ratios contained in the log-linearized budget constraint, (13), as a function of model parameters and the steady-state debt-GDP ratio.

Appendix A.2 derives the quadratic approximation to utility as

$$
\begin{aligned}
\Gamma= & -\bar{N}^{1+\varphi} \frac{1}{2} E_{0} \sum_{t=0}^{\infty} \beta^{t}\left(\sigma \theta\left(\widehat{C}_{t}-\widehat{C}_{t}^{*}\right)^{2}+\sigma(1-\theta)\left(\widehat{G}_{t}-\widehat{G}_{t}^{*}\right)^{2}\right. \\
& \left.+\varphi\left(\widehat{Y}_{t}-\widehat{Y}_{t}^{*}\right)^{2}+\frac{\epsilon}{\gamma} \pi_{t}^{2}\right)+t i p+O[2],
\end{aligned}
$$

where tip captures terms which are independent of policy and $O[2]$ terms which are higher than second order. It contains quadratic terms in price inflation reflecting the costs of price dispersion induced by inflation in the presence of nominal inertia, as well as terms in the consumption, government spending, and output gaps (i.e., the difference between the actual value of the variable and its optimal value). The weights attached to each element are a function of deep model parameters.

\subsection{Gap Variables}

We have derived welfare based on various gaps, so we now proceed to rewrite our model in terms of the same gap variables to facilitate derivation of bargained 
policy outcomes. The consumption Euler equation can be written in gap form as

$$
\left(\widehat{C}_{t}-\widehat{C}_{t}^{*}\right)=E_{t}\left(\widehat{C}_{t+1}-\widehat{C}_{t+1}^{*}\right)-\frac{1}{\sigma}\left[\left(r_{t}-r_{t}^{*}\right)-E_{t}\left(\pi_{t+1}\right)\right],
$$

where $r_{t}^{*}=\sigma \frac{1+\varphi}{\sigma+\varphi}\left[E_{t}\left(a_{t+1}\right)-a_{t}\right]+\sigma\left[E_{t}\left(\widehat{\xi}_{t+1}\right)-\widehat{\xi}_{t}\right]-\frac{\sigma}{\sigma+\varphi}\left[E_{t}\left(\widehat{\xi}_{t+1}^{N}\right)-\widehat{\xi}_{t}^{N}\right]$ is the natural/efficient rate of interest.

The NKPC can be written in gap form as

$$
\pi_{t}=\beta E_{t} \pi_{t+1}+\gamma\left[\varphi\left(\widehat{Y}_{t}-\widehat{Y}_{t}^{*}\right)+\sigma\left(\widehat{C}_{t}-\widehat{C}_{t}^{*}\right)+\frac{\bar{\tau}}{1-\bar{\tau}}\left(\widehat{\tau}_{t}-\widehat{\tau}_{t}^{*}\right)\right],
$$

where, following Benigno and Woodford (2004) we define, $\frac{\bar{\tau}}{1-\bar{\tau}} \widehat{\tau}_{t}^{*}=\widehat{\mu}_{t}$. In other words, we are defining our "efficient" tax rate as the tax rate required to perfectly offset the impact of a cost-push shock. ${ }^{11}$ If we had access to a lump-sum tax to finance the budget deficit, then this would be the optimal tax rate. However, given the need to finance the government liabilities through distortionary taxation, actual tax rates are likely to deviate from the level required to perfectly offset such shocks. Appendix A.3 rewrites the budget constraint in gap form as

$$
\begin{aligned}
\widehat{b}_{t-1}-\pi_{t}= & \beta \widehat{b}_{t}-\beta E_{t}\left[\pi_{t+1}+\sigma\left(\widehat{C}_{t+1}-\widehat{C}_{t+1}^{*}\right)\right]+ \\
& p s_{t}-f_{t}+\sigma \beta\left(\widehat{C}_{t}-\widehat{C}_{t}^{*}\right),
\end{aligned}
$$

with the primary surplus defined as

$$
p s_{t}=\frac{\bar{w} \bar{N} \bar{\tau}}{\bar{b}}\left[(1+\varphi)\left(\widehat{Y}_{t}-\widehat{Y}_{t}^{*}\right)+\frac{1}{1-\bar{\tau}}\left(\widehat{\tau}_{t}-\widehat{\tau}_{t}^{*}\right)+\sigma\left(\widehat{C}_{t}-\widehat{C}_{t}^{*}\right)\right]-\frac{\bar{G}}{\bar{b}}\left(\widehat{G}_{t}-\widehat{G}_{t}^{*}\right),
$$

and

$$
f_{t}=-[\sigma+(1-\sigma)(1-\beta)]\left(\frac{(1+\varphi)}{\sigma+\varphi} a_{t}-\frac{\widehat{\xi}_{t}^{N}}{\sigma+\varphi}\right)-\frac{\bar{w} \bar{N}}{\bar{b}} \widehat{\mu}_{t}-\sigma \beta\left(1-\rho_{\xi}\right) \widehat{\xi}_{t},
$$

which captures the extent to which the various shocks hitting our model have fiscal consequences. This is not a new shock, but is where all the shocks of the model appear once the model has been rewritten in gap form. The reason why the shocks can be located only in the budget constraint is that it would be possible, given the instruments available to the policy makers, to offset the welfare costs of nominal inertia in the face of shocks and implement the social planner's allocation, if it was not necessary to also satisfy the government's intertemporal budget constraint. Therefore, shocks matter in this model, only to the extent that they have fiscal consequences. In light of this, we simplify the analysis by assuming that government debt is the only state variable in the model and focus on bargaining over how to deal with the debt disequilibrium that has emerged as a result of those shocks. 


\subsection{Policy Makers' Preferences}

Policy maker preferences take the same basic form as our measure of social welfare but with a crucial difference, player $i$ can potentially place different weights on the elements of social welfare,

$$
\Gamma^{i}=-\bar{N}^{1+\varphi} \frac{1}{2} E_{0} \sum_{t=0}^{\infty} \beta^{t} l\left(x_{i}^{c}, x_{i}^{g}, x_{i}^{y}, x_{i}^{\pi}\right)+t i p+O[2],
$$

with

$$
\begin{aligned}
l\left(x_{i}^{c}, x_{i}^{g}, x_{i}^{y}, x_{i}^{\pi}\right)= & \sigma \theta x_{i}^{c}\left(\widehat{C}_{t}-\widehat{C}_{t}^{*}\right)^{2}+\sigma(1-\theta) x_{i}^{g}\left(\widehat{G}_{t}-\widehat{G}_{t}^{*}\right)^{2} \\
& +\varphi x_{i}^{y}\left(\widehat{Y}_{t}-\widehat{Y}_{t}^{*}\right)^{2}+x_{i}^{\pi} \frac{\epsilon}{\gamma} \pi_{t}^{2} .
\end{aligned}
$$

When $x_{i}^{z} \neq 1$, for any $z=c, g, y, \pi$ and $i=1,2$, then policy maker preferences deviate from social welfare and if $x_{1}^{z} \neq x_{2}^{z}$ then there is scope for conflict when bargaining over policy. In the numerical section below, we shall highlight conflict over the importance given to inflation in the two players' objective functions, as well as conflict over the importance of fluctuations of specific policy instruments. However, the bargaining game considered below allows for conflict across the multiple elements of social welfare. We could have focused on a particular micro-foundation for such conflict, such as, for example, parties reflecting the preferences of two groups of households with different attitudes to the size of the state, but that would have necessarily limited the generality of the results. Instead, in line with our broad interpretation of the kinds of conflict that can drive negotiated outcomes, we prefer to allow for a wide range of differences in policy maker preferences.

\section{THE DETERMINATION OF POLICY}

\subsection{The Model in Matrix Form}

In this subsection, we rewrite the model in a recursive form suitable for defining the constraints in the bargaining game implied by our description of the economy. Having already recast the model in terms of the gap variables contained in the welfare function, we proceed by forming a "guess" of the relationship between expectations and the state variable to eliminate expectations from the structural equations. The coefficients of these guesses will then be determined as part of the fixed-point solution to the bargaining game. In gap form, the instruments proposed by player $i$ are $c_{i t}^{g}=\widehat{C}_{t}-\widehat{C}_{t}^{*}, g_{i t}^{g}=\widehat{G}_{t}-\widehat{G}_{t}^{*}$ and $\tau_{i t}^{g}=\widehat{\tau}_{t}-\widehat{\tau}_{t}^{*} \cdot{ }^{12}$

In a linear-quadratic problem (without bargaining), the only equilibrium strategies, if they exist, are linear. Since we focus on bargaining strategies which are also linear, it must be that the forecasts on inflation and the control at time $t$ are linear functions of the future debt $\widehat{b}_{t}=\mathbf{S}_{t}$

$$
\begin{gathered}
E_{t} \pi_{t+1}=f^{i} \mathbf{S}_{t}, \\
E_{t} c_{t+1}^{g}=c^{i} \mathbf{S}_{t},
\end{gathered}
$$


where $f^{i}$ and $c^{i}$, with $i=1,2$, are coefficients to be determined. ${ }^{13}$ The superscript $i$ indicates the identity of the policy maker who made the policy mix $u_{i t}$ at $t$. Hence, we allow players' expectation coefficients to (potentially) differ depending on which policy (player 1 or 2's) is implemented at $t$, given the state $\mathbf{S}_{t-1}$. In equilibrium, we will show that players will have the same forecast coefficients, $f^{1}=f^{2}$ and $c^{1}=c^{2}$, independently of who implemented the last successful policy mix (this is fully captured in the forecasts by the future state $\mathbf{S}_{t}$ ). ${ }^{14}$

Using these "guesses" for consumption and inflation expectations implies that the budget constraint, (15), can be written as follows

$$
\mathbf{B 0}^{i} \mathbf{S}_{t}=\mathbf{S}_{t-1}+\mathbf{B} 2 \mathbf{u}_{i t}
$$

with

$$
\begin{gathered}
\mathbf{S}_{t-1}=\left[\widehat{b}_{t-1}\right], \\
\mathbf{u}_{i t}=\left[\begin{array}{c}
c_{i t}^{g} \\
\tau_{i t}^{g} \\
g_{i t}^{g}
\end{array}\right], \\
\mathbf{B 0}^{i}=\left[\begin{array}{ll}
\beta\left(1-\sigma c^{i}\right)
\end{array}\right], \\
\mathbf{B} 2=\left[\begin{array}{lll}
\mathbf{B} 2_{1,1} & \mathbf{B} 2_{1,2} & \mathbf{B} 2_{1,3}
\end{array}\right],
\end{gathered}
$$

where

$$
\begin{aligned}
\mathbf{B} 2_{1,1} & =\frac{-(\varphi \theta+\sigma)\left((1+\gamma) \frac{\bar{B}}{\bar{Y}}+1-\theta\right)-\theta(1-\theta)-(1-\beta) \theta \frac{\bar{B}}{\bar{Y}}+\beta \varphi \theta \frac{\bar{B}}{\bar{Y}}}{\frac{\bar{B}}{\bar{Y}}}, \\
\mathbf{B} 2_{1,2} & =\frac{\left(-(2-\theta)-(1-\beta+\gamma) \frac{\bar{B}}{\bar{Y}}\right)\left((1-\beta) \frac{\bar{B}}{\bar{Y}}+(1-\theta)\right)}{\overline{\bar{B}}}, \\
\mathbf{B} 2_{1,3} & =\frac{\left((1+\varphi)\left(\theta-(1-\beta) \frac{\bar{B}}{\bar{Y}}\right)-\varphi\left(1+\gamma \frac{\bar{B}}{\bar{Y}}\right)\right)(1-\theta)}{\frac{\bar{B}}{\bar{Y}}} .
\end{aligned}
$$

Then, if players implement party $i$ 's proposed policy $\mathbf{u}_{i t}$ at $t$, the state $\mathbf{S}_{t}$ becomes

$$
\mathbf{S}_{t}=\mathbf{D} 1^{i} \mathbf{S}_{t-1}+\mathbf{D} 2^{i} \mathbf{u}_{i t}
$$

with

$$
\begin{gathered}
\mathbf{D} \mathbf{~}^{i}=\left[\mathbf{B} \mathbf{0}^{i}\right]^{-1}, \\
\mathbf{D 2}^{i}=\left[\mathbf{B 0}^{i}\right]^{-1} \mathbf{B} 2,
\end{gathered}
$$


while the NKPC, (14), in matrix form is given by

$$
E_{t} \pi_{t+1}=\mathbf{A} \mathbf{1} \pi_{t}+\mathbf{A} \mathbf{2} \mathbf{u}_{i t},
$$

where

$$
\begin{aligned}
& \mathbf{A} \mathbf{1}=\left[\frac{1}{\beta}\right], \\
& \mathbf{A} \mathbf{2}=\left[-\frac{\gamma(\varphi \theta+\sigma)}{\beta}-\frac{\gamma\left((1-\beta) \frac{\bar{B}}{\bar{Y}}+(1-\theta)\right)}{\beta}-\frac{\gamma \varphi(1-\theta)}{\beta}\right] .
\end{aligned}
$$

The latter, together with the inflation forecast, (18), implies that inflation can be written as

$$
\pi_{t}=\mathbf{C} 1^{i} \mathbf{S}_{t-1}+\mathbf{C} 2^{i} \mathbf{u}_{i t}
$$

where

$$
\begin{gathered}
\mathbf{C} \mathbf{1}^{i}=[\mathbf{A} \mathbf{1}]^{-1}\left[f^{i} \mathbf{D} 1^{i}\right], \\
\mathbf{C} 2^{i}=[\mathbf{A} \mathbf{1}]^{-1}\left[f^{i} \mathbf{D} 2^{i}-\mathbf{A} 2\right] .
\end{gathered}
$$

Therefore, equation (23) describes the evolution of the state, government debt, while (25) defines the inflation outcome, both given the inherited state and conditional on the policy mix proposed by player $i$ being implemented. These equations will act as constraints on the bargaining game outlined below.

We can similarly define the players' per-period objective function in matrix form, for player $i$, as

$$
l_{i}\left(x_{i}^{c}, x_{i}^{g}, x_{i}^{y}, x_{i}^{\pi}\right)=\pi_{t} \mathbf{R}^{i} \pi_{t}+\mathbf{u}_{i t}^{\prime} \mathbf{Q}^{i} \mathbf{u}_{i t},
$$

and for player $j$ as

$$
l_{j}\left(x_{i}^{c}, x_{i}^{g}, x_{i}^{y}, x_{i}^{\pi}\right)=\pi_{t} \mathbf{R}^{j} \pi_{t}+\mathbf{u}_{i t}^{\prime} \mathbf{Q}^{j} \mathbf{u}_{i t},
$$

where $\mathbf{u}_{i t}$ is in (22), $\mathbf{R}^{i}=x_{i}^{\pi}\left[\frac{\epsilon}{\gamma}\right]$ and

$$
\mathbf{Q}^{i}=\left[\begin{array}{ccc}
\theta\left(\sigma x_{i}^{c}+\varphi \theta x_{i}^{y}\right) & 0 & 2(1-\theta) \theta \varphi x_{i}^{y} \\
0 & 0 & 0 \\
0 & 0 & (1-\theta)\left(\sigma x_{i}^{g}+\varphi x_{i}^{y}(1-\theta)\right)
\end{array}\right]
$$

with $i, j=1,2$ and $i \neq j .{ }^{15}$

\subsection{The Bargaining Game}

In this subsection, we describe the structure of the bargaining game, before solving this problem in the next subsection. For any state $\mathbf{S}_{t-1}$, there is a bargaining stage where players negotiate the policy mix, following a standard alternatingoffer bargaining procedure (Rubinstein (1982)) with the crucial novelty that any 
agreement reached in a bargaining stage affects future bargaining possibilities (via the state variable, $\mathbf{S}_{t}$, in this case government debt, $\widehat{b}_{t-1}$, see (21)). We assume that the first player to make a proposal is randomly chosen. Let $q^{i}$ be the constant (and unconditional) probability that player $i$ is chosen to make the first proposal in a bargaining stage, with $i=1,2$ and $q^{1}+q^{2}=1$. The first mover, say player $i$, makes a proposal over the values of the set of policy instruments, $u_{i t}$, to player $j$ $(i, j=1,2$ and $i \neq j)$, which can be either accepted or rejected.

In case of an acceptance, the bargaining stage ends and the agreement (or policy) is implemented. The utility players obtain in this bargaining stage is as in (26) and (27), replicated below

$$
\begin{aligned}
& l_{i}\left(x_{i}^{c}, x_{i}^{g}, x_{i}^{y}, x_{i}^{\pi}\right)=\pi_{t} \mathbf{R}^{i} \pi_{t}+\mathbf{u}_{i t}^{\prime} \mathbf{Q}^{i} \mathbf{u}_{i t}, \\
& l_{j}\left(x_{i}^{c}, x_{i}^{g}, x_{i}^{y}, x_{i}^{\pi}\right)=\pi_{t} \mathbf{R}^{j} \pi_{t}+\mathbf{u}_{i t}^{\prime} \mathbf{Q}^{j} \mathbf{u}_{i t} .
\end{aligned}
$$

The policy $\mathbf{u}_{i t}$ will affect the state variable for the next period (a quarter of a year in our numerical calibration), via (23). In the new period, with state $\mathbf{S}_{t}$, another bargaining stage will take place where players will attempt to find a new agreement.

In case of a rejection, instead, the state remains unchanged and after a short interval of time, player $j$ can make a counteroffer, $\mathbf{u}_{j t}$ which again can either be accepted or rejected. Disutility per-bargaining round in disagreement is $X(1-$ $\delta)<0$, with $i, j=1,2$. In our model, there are two discount factors, $\beta$ and $\delta$, to capture the different intervals of time. The first, $\beta$, reflects the usual discounting of time in our New Keynesian model and is applied between bargaining stages (as shown in (1)). The second, $\delta$, captures the impatience of the players across bargaining rounds within a bargaining stage. As shown in Muthoo (1999, p. 303) in the context of repeated bargaining games, the restriction of $\delta>\beta$ is not only more realistic (it is quicker to make a counteroffer than starting a new bargaining stage), but also supports more economically interesting solutions where players make concessions rather than implementing extreme (take-it-or-leave-it) offers. In our model, we will consider the limit where bargaining frictions tend to disappear (i.e., $\delta \rightarrow 1$ ). As a result, parties have the opportunity to almost instantly make a counteroffer after any rejection within the bargaining stage (and who is chosen to make the initial proposal becomes immaterial). ${ }^{16}$

The focus is on stationary MPE, that is, a Nash equilibrium with stationary Markov strategies in each subgame. With stationary Markov strategies, the only relevant variable affecting players' behavior is the state variable, government debt, $\widehat{b}_{t-1}$. The stationary strategies specify the same action for the same value of the state, independently of time. In our framework, a strategy consists in pair of functions: a proposal (on the policy mix) and a response strategy.

In an arbitrary (stationary) MPE, let $V^{i}\left(\mathbf{S}_{t-1}\right)\left(W^{i}\left(\mathbf{S}_{t-1}\right)\right.$, respectively) be the optimal discounted payoff of player $i$ when $i$ proposes $\mathbf{u}_{i t}$ (responds) at $t$ and the state variable is $\mathbf{S}_{t-1}, i=1,2$. These must be the optimal payoffs, given that an 
offer can be either accepted or rejected

$$
\begin{aligned}
V^{i}\left(\mathbf{S}_{t-1}\right) & =\max \left\{V^{i \prime}\left(\mathbf{S}_{t-1}\right), X(1-\delta)+\delta W^{i}\left(\mathbf{S}_{t-1}\right)\right\}, \\
W^{j}\left(\mathbf{S}_{t-1}\right) & =\max \left\{W^{j \prime}\left(\mathbf{S}_{t-1}\right), X(1-\delta)+\delta V^{j}\left(\mathbf{S}_{t-1}\right)\right\},
\end{aligned}
$$

where $V^{i \prime}\left(\mathbf{S}_{t-1}\right)$ and $W^{j \prime}\left(\mathbf{S}_{t-1}\right)$ are the sum of discounted payoffs in the case of an acceptance, while the second terms in brackets in (29) and (30) represent the payoffs when there is a rejection. For the latter, the payoffs to the proposer, in the event of rejection, are made up of the (per-bargaining-round) disutility of disagreement, $X(1-\delta)$, and the (discounted) expected payoffs from being a responder in the next bargaining round, $\delta W^{i}\left(\mathbf{S}_{t-1}\right)$. While the payoffs to a responder who rejects the proposal are the (per-bargaining-round) disutility of disagreement, $X(1-\delta)$, and the expected payoffs from being a proposer in the next bargaining round, $\delta V^{j}\left(\mathbf{S}_{t-1}\right)$. Hence, following a standard alternating-offer procedure, in the event of a rejection, the players switch roles (the player who rejected the proposal now can make a counteroffer). The payoffs in case of an acceptance, $V^{i \prime}\left(\mathbf{S}_{t-1}\right)$ and $W^{j \prime}\left(\mathbf{S}_{t-1}\right)$, have recursive structures

$$
\begin{gathered}
V^{i \prime}\left(\mathbf{S}_{t-1}\right)=A-\min _{\mathbf{u}_{i t}}\left(b\left(\pi_{t} \mathbf{R}^{i} \pi_{t}+\mathbf{u}_{i t}^{\prime} \mathbf{Q}^{i} \mathbf{u}_{i t}\right)-\beta E_{t} C^{i}\left(\mathbf{S}_{t}\right)\right), \\
\left.W^{j \prime}\left(\mathbf{S}_{t-1}\right)=A-b\left(\pi_{t} \mathbf{R}^{j} \pi_{t}+\mathbf{u}_{i t}^{\prime} \mathbf{Q}^{j} \mathbf{u}_{i t}\right)+\beta E_{t} C^{j}\left(\mathbf{S}_{t}\right)\right),
\end{gathered}
$$

where $A$ is the constant term from the Taylor approximation to utility, $b=\frac{1}{2} \bar{N}^{1+\varphi}$ and $E_{t} C^{i}\left(\mathbf{S}_{t}\right)\left(E_{t} C^{j}\left(\mathbf{S}_{t}\right)\right.$, respectively) indicates the expected value of the game continuation to $i$ ( $j$, respectively) at $t .{ }^{17}$ This can be written as a weighted sum of the expected payoffs to a proposer and a responder, with weights given by the probabilities of being a proposer and a responder

$$
E_{t} C^{i}\left(\mathbf{S}_{t}\right)=q^{i} V^{i}\left(\mathbf{S}_{t}\right)+\left(1-q^{i}\right) W^{i}\left(\mathbf{S}_{t}\right) .
$$

An offer $\mathbf{u}_{i t}$ will be accepted if the so-called acceptance condition holds

$$
W^{j^{\prime}}\left(\mathbf{S}_{t-1}\right) \geq X(1-\delta)+\delta V^{j}\left(\mathbf{S}_{t-1}\right) \text {. }
$$

This states that player $j$ accepts $\mathbf{u}_{i t}$, given $\mathbf{S}_{t-1}$, if his discounted payoff as a responder, $W^{j}\left(\mathbf{S}_{t-1}\right)$, is not smaller than the discounted payoff he would get by rejecting $\mathbf{u}_{i t}$ and making a counteroffer in the next period, $\delta V^{j}\left(\mathbf{S}_{t-1}\right)$.

If condition (34) does not hold, the policy $\mathbf{u}_{i t}$ is rejected, the state is assumed to be unchanged, and the roles of the proposer and the responder are swapped, using (29) and (30), then

$$
V^{i}\left(\mathbf{S}_{t-1}\right)=X(1-\delta)+\delta W^{i}\left(\mathbf{S}_{t-1}\right) \text { and } W^{j}\left(\mathbf{S}_{t-1}\right)=X(1-\delta)+\delta V^{j}\left(\mathbf{S}_{t-1}\right) .
$$

It is intuitive that in equilibrium delays cannot be profitable, if the state remains unchanged and the per-bargaining-round disutility of disagreement is sufficiently large. ${ }^{18}$ Parties can always invest in future bargaining possibilities so as to avoid 
costly delays. ${ }^{19,20}$ This implies that in equilibrium,

$$
\begin{aligned}
\mathbf{u}_{i t}\left(\mathbf{S}_{t-1}\right) & \in \arg \max A-\left(b\left(\pi_{t} \mathbf{R}^{i} \pi_{t}+\mathbf{u}_{i t}^{\prime} \mathbf{Q}^{i} \mathbf{u}_{i t}\right)-\beta E_{t} C^{i}\left(\mathbf{S}_{t}\right)\right) \\
\text { s.t., } W^{j}\left(\mathbf{S}_{t-1}\right) & \geq X(1-\delta)+\delta V^{j}\left(\mathbf{S}_{t-1}\right),
\end{aligned}
$$

given the equation of motion (23) for $\mathbf{S}_{t}$,

$$
\mathbf{S}_{t}=\mathbf{D} 1^{i} \mathbf{S}_{t-1}+\mathbf{D} 2^{i} \mathbf{u}_{i t}
$$

$\pi_{t}$, which evolves according to (25)

$$
\pi_{t}=\mathbf{C} 1^{i} \mathbf{S}_{t-1}+\mathbf{C} 2^{i} \mathbf{u}_{i t},
$$

and the expectations of $\pi_{t+1}$ and $c_{t+1}^{g}$, as in (18) and (19). This problem consists of a system of constrained recursive optimizations, with an extra layer of complexity: the constraints, that is, the acceptance conditions (34), embody both another recursive problem (via $V^{j}\left(\mathbf{S}_{t-1}\right)$ ) and the expectations (18) and (19).

\subsection{MPE Policies}

In this section, we find the optimal policies using the guess and verify method (and a fixed-point argument).

Since the focus is on linear time-invariant equilibrium strategies, the value function for player $i, V^{i}\left(\mathbf{S}_{t-1}\right)$, and his optimal discounted payoff as a responder, $W^{i}\left(\mathbf{S}_{t-1}\right)$, must be quadratic

$$
\begin{aligned}
V^{i}\left(\mathbf{S}_{t-1}\right) & =A-b \mathbf{S}_{t-1}^{\prime} \Phi^{i} \mathbf{S}_{t-1}, \\
W^{i}\left(\mathbf{S}_{t-1}\right) & =A-b \mathbf{S}_{t-1}^{\prime} \boldsymbol{\mu}^{i} \mathbf{S}_{t-1},
\end{aligned}
$$

where $\boldsymbol{\Phi}^{i}$ and $\boldsymbol{\mu}^{i}$, with $i=1,2$ are coefficients to be determined (or "guesses"). ${ }^{21}$ When players define their strategies, they have to consider the value of the continuation game, $E_{t} C^{i}\left(\mathbf{S}_{t}\right)$. Given (33), this is a linear combination of quadratic functions, hence, $E_{t} C^{i}\left(\mathbf{S}_{t}\right)$ must be also a quadratic function of the state $\mathbf{S}_{t}$

$$
E_{t} C^{i}\left(\mathbf{S}_{t}\right)=A-b \mathbf{S}_{t} \boldsymbol{\beta}^{i} \mathbf{S}_{t},
$$

where $\boldsymbol{\beta}^{i}=q^{i} \boldsymbol{\Phi}^{i}+\left(1-q^{i}\right) \boldsymbol{\mu}^{i}$, with $i=1,2$.

Let $\mathbf{X}_{11}$ indicate the first element of matrix/vector $\mathbf{X}$. Then the MPE solution is derived in the following proposition.

PROPOSITION 1. For $\delta \rightarrow 1$, the MPE policies are given by

$$
\mathbf{u}_{i t}=\mathbf{O} 1^{i} \mathbf{S}_{t-1},
$$

with

$$
\boldsymbol{\mu}^{j}=\delta \boldsymbol{\Phi}^{j},
$$

where the payoff coefficients are

$$
\boldsymbol{\Phi}^{i}=\mathbf{P} \mathbf{0}^{i^{\prime}} \mathbf{R}^{i} \mathbf{P} \mathbf{0}^{i}+\mathbf{O} 1^{i^{\prime}} Q^{i} \mathbf{O} 1^{i}+\beta \mathbf{G} \mathbf{1}^{i^{\prime}} \boldsymbol{\beta}^{i} \mathbf{G} \mathbf{1}^{i},
$$




$$
\boldsymbol{\mu}^{j}=\mathbf{P} \mathbf{0}^{i^{\prime}} \mathbf{R}^{j} \mathbf{P} \mathbf{0}^{i}+\mathbf{O 1}^{i^{\prime}} Q^{j} \mathbf{O} 1^{i}+\beta \mathbf{G} \mathbf{1}^{i^{\prime}} \boldsymbol{\beta}^{j} \mathbf{G} \mathbf{1}^{i},
$$

with $\boldsymbol{\beta}^{i}=q^{i} \boldsymbol{\Phi}^{i}+\left(1-q^{i}\right) \boldsymbol{\mu}^{i}$; the forecast coefficients are

$$
\begin{aligned}
& f^{1}=f^{2}=q^{i} \mathbf{P} \mathbf{0}^{i}+\left(1-q^{i}\right) \mathbf{P} \mathbf{0}^{j}, \\
& c^{1}=c^{2}=q^{i} \mathbf{O} 1_{11}^{i}+\left(1-q^{i}\right) \mathbf{O} 1_{11}^{j},
\end{aligned}
$$

and $\mathbf{O 1}^{i}, \mathbf{G 1}{ }^{i}$, and $\mathbf{P 0}{ }^{i}$ are defined in (B11), (B13), and (B15), with $i, j=1,2$, and $i \neq j$.

Proof. See Appendix B.

It is worth to highlight some features of the solution. First, generally the expectations on $\pi_{t+1}$ and $c_{t+1}^{g}$ are time-invariant linear functions of the state, $\mathbf{S}_{t}$, as shown in (40) and (41). Since frictions disappear and there are no delays in equilibrium, the expectation coefficients remain invariant $\left(f^{1}=f^{2}\right.$ and $\left.c^{1}=c^{2}\right)$. Second, given the focus on frictionless bargaining $(\delta \rightarrow 1)$, for a given state, $\mathbf{S}_{t-1}$, players receive the same payoffs when making an offer or responding $\left(\boldsymbol{\mu}^{j} \rightarrow \boldsymbol{\Phi}^{j}\right)$. Finally, as shown in the appendix, generally for $\delta<1$, there may not be timeinvariant linear policies in equilibrium or players may not make any concession in equilibrium. However, in the most realistic case in which the frictions in the bargaining stage disappear $(\delta \rightarrow 1)$, players implement time-invariant policies and make concessions. This is the richest solution in terms of the interplay of forces in the game, and it is analyzed in the next section.

\section{NUMERICAL EXAMPLES}

In this section, we outline the response of the model to a series of shocks which have had fiscal consequences and illustrate the proposition established above. Employing the econometric estimates in Leith and Malley (2005), we adopt the following parameter set, $\varphi=1, \sigma=2, \mu=1.2, \bar{\epsilon}=6, \beta=0.99$, and, following Gali (1994) the share of government consumption in GDP, $1-\theta=0.25$. In our benchmark simulations, we assume a degree of price stickiness of $\theta_{p}=0.75$, which implies that an average contract length of 1 year, and an debt-GDP ratio of $60 \%$. We also focus on the most interesting case in which a bargaining round is infinitesimally short $(\delta \rightarrow 1)$, hence counteroffer can be made quickly after a rejection. $^{22}$

Conflict over Inflation Conservatism. Although our bargaining game is consistent with conflict over any element(s) of social welfare, in this section, we begin by focusing on an example where there is only conflict over the relative weight given to inflation. Specifically, we set the weights on all elements of welfare, other than inflation, equal to that which would be chosen by a benevolent policy maker $\left(x_{i}^{z}=1\right.$ for $z=c, y, g$ and $i=1,2$ ), while for inflation we consider an equal but opposite deviation from social welfare weights in evaluating the costs of inflation, $x_{i}^{\pi}=(1+x)$ and $x_{j}^{\pi}=(1-x)$ with $i, j=1,2$ and $i \neq j$. That is, player $i$ is more concerned with stabilizing inflation following shocks than player $j$ and their 
objective functions reduce to

$$
\Gamma^{i}=-\bar{N}^{1+\varphi} \frac{1}{2} E_{0} \sum_{t=0}^{\infty} \beta^{t} l(1,1,1,1+x)+t i p+O[2]
$$

with

$$
\begin{aligned}
l(1,1,1,1+x)= & \sigma \theta\left(\widehat{C}_{t}-\widehat{C}_{t}^{*}\right)^{2}+\sigma(1-\theta)\left(\widehat{G}_{t}-\widehat{G}_{t}^{*}\right)^{2} \\
& +\varphi\left(\widehat{Y}_{t}-\widehat{Y}_{t}^{*}\right)^{2}+(1+x) \frac{\epsilon}{\gamma} \pi_{t}^{2}
\end{aligned}
$$

and,

$$
\Gamma^{j}=-\bar{N}^{1+\varphi} \frac{1}{2} E_{0} \sum_{t=0}^{\infty} \beta^{t} l(1,1,1,1-x)+t i p+O[2],
$$

with

$$
\begin{aligned}
l(1,1,1,1-x)= & \sigma \theta\left(\widehat{C}_{t}-\widehat{C}_{t}^{*}\right)^{2}+\sigma(1-\theta)\left(\widehat{G}_{t}-\widehat{G}_{t}^{*}\right)^{2} \\
& +\varphi\left(\widehat{Y}_{t}-\widehat{Y}_{t}^{*}\right)^{2}+(1-x) \frac{\epsilon}{\gamma} \pi_{t}^{2},
\end{aligned}
$$

respectively. Therefore, as we increase $x$ we increase the weight given to inflation stabilization by player $i$, while reducing it, proportionately, for player $j$. One way of motivating such a setup would be to allow the elasticity of demand for monopolistic firms' products to be of one of two types - high or low. Party $i$ represents the interests of those workers employed by high-elasticity firms, while party $j$ represents the workers employed by the correspondingly lower elasticity firms. Alternatively, the conflict could between a CB and the government where they do not share the same degree of inflation conservatism, but where they still agree a common set of macroeconomic policies before implementing their respective policy instruments. ${ }^{23}$

As shown in the proof of Proposition 1, the solution to the model will take the form

$$
\begin{aligned}
\mathbf{u}_{i t} & =\left[\begin{array}{c}
c_{i t}^{g} \\
\tau_{i t}^{g} \\
g_{i t}^{g}
\end{array}\right]=\mathbf{O 1}^{i} \mathbf{S}_{t-1}, \\
\pi_{t} & =\mathbf{P O}^{i} \mathbf{S}_{t-1}, \\
\mathbf{S}_{t} & =\mathbf{G 1}^{i} \mathbf{S}_{t-1},
\end{aligned}
$$

see (B10)-(B15) in Appendix B. Since debt is the only state variable in our model, these solution matrices will relate the solution of the endogenous variables in our model to the degree of debt disequilibrium.

Figure 1 plots these solution coefficients as a function of $x$, the degree to which policy makers disagree over the importance of inflation, for three alternative steady-state debt-GDP ratios $(20 \%, 50 \%$, and $80 \%$ indicated as L, M, and 

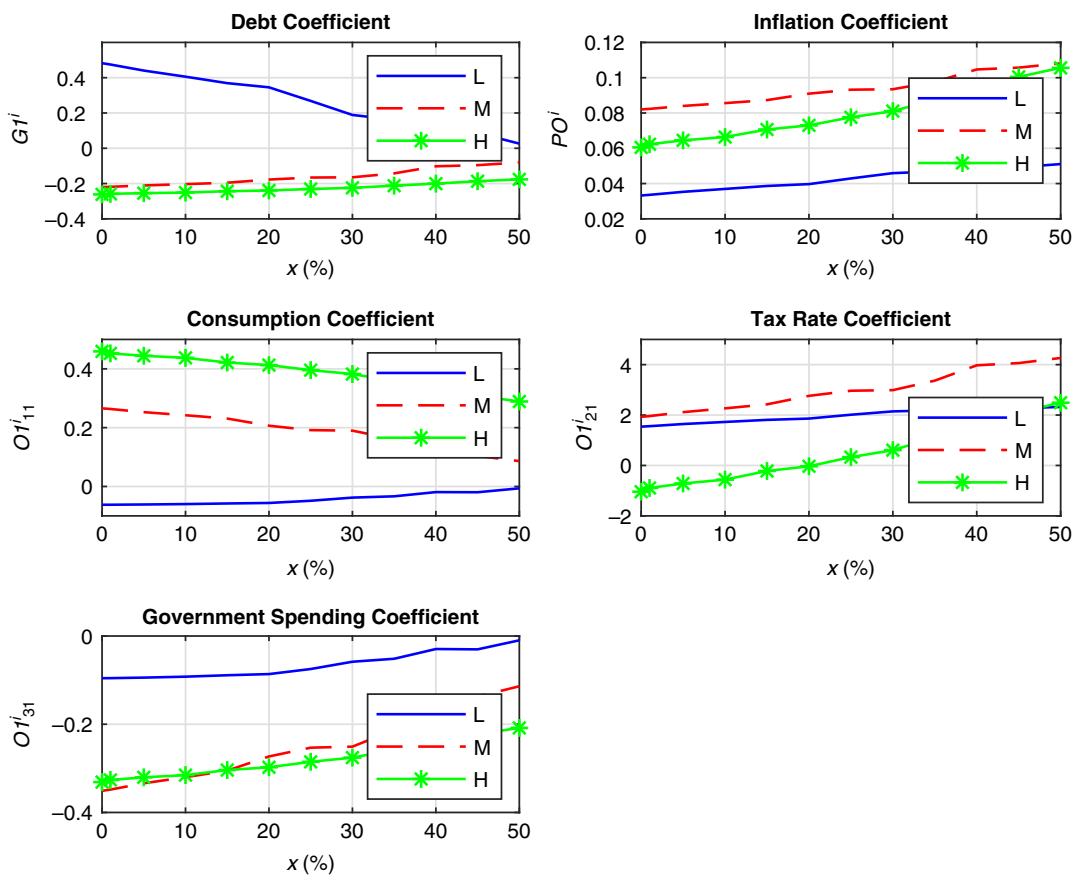

Notes: The figure plots equilibrium coefficients that multiply debt, $b_{t-1}$, against the degree of conflict, $x$, expressed as a percentage. The solid blue line-low debt of $20 \%$ of GDP, red dashed line-medium debt of $50 \%$ of GDP, green circles-high debt of $80 \%$ of GDP.

FIGURE 1. MPE coefficients and conflict over inflation stabilization.

$\mathrm{H}$, respectively). The point of intersection with the $\mathrm{y}$-axis describes the model solution in the absence of any conflict, $x=0$. It, therefore, corresponds to the usual case of monetary and fiscal policies being conducted by a benevolent policy maker without the need for any bargaining - this case is considered in Leith and Wren-Lewis (2013). It is helpful to describe the policy outcomes this implies to serve as a benchmark against which to compare solutions which introduce conflict and bargaining to the policy process. The standard policy problem implies that a shock which raises debt will result in the policy maker cutting government consumption. The remainder of the policy mix depends, crucially, on the level of debt since this affects the relative efficacy of alternative policy instruments. At lower debt levels, spending cuts are accompanied by tax rises and a tightening of monetary policy to moderate inflation. At higher debt levels, monetary policy becomes a far more effective means of stabilizing debt, and interest rates are cut to boost the tax base and reduce debt service costs. In this case, tax rates may actually fall to mitigate the rise in inflation caused by the relaxation of monetary policy.

In the absence of conflict/bargaining, higher debt levels can actually lead to the policy maker overcorrecting by reducing debt below steady state in the period 
after a shock raises debt. Leith and Wren-Lewis (2013) discuss this desire to overcorrect debt in a model without political conflict. It arises under a time-consistent policy as manipulating endogenous state variables is the only way a policy maker can influence expectations. Since, in equilibrium, inflation is rising in debt levels, a fall in debt relative to steady state gives rise to a deflation. Given the forwardlooking NKPC, the expectation that debt will be driven below steady state in the future reduces inflationary expectations, improving policy trade-offs for the policy maker today.

Introducing conflict/bargaining shows that, as the degree of inflation aversion diverges across policy makers, the absolute value of the debt coefficient falls. This implies that the level of debt is stabilized faster following the shock, but with less of the overshooting seen under medium to high debt levels in the absence of conflict/bargaining. Moreover, the policy function relating inflation to debt has a higher coefficient across all three debt levels (L, M, and $\mathrm{H}$ ) as the extent of conflict rises. In other words, in this case, conflict over inflation results in higher inflation, but with less attempt to influence inflationary expectations by reducing debt further than is necessary. These effects arise from the nature of the political conflict we have introduced.

The player with the lower weight attached to inflation is now more content to utilize surprise inflation to stabilize debt and less concerned about mitigating its effects by over-stabilizing debt in the short run. Accordingly, such a player may seek to propose policies which reduce the size of other welfare-relevant gaps, namely consumption and government spending. Indeed, this is what we see. In the policy agreed under political conflict, the policy makers stabilize private and public consumption gaps to a greater extent (which benefits both players equally, cet. par.) and rely on movements in taxation (which have no direct welfare consequences) to a greater extent. In other words, the less inflation-averse player achieves the agreed increased use of inflation as a public debt stabilization instrument, using government spending and reduced debt service costs (through an accommodative monetary policy) less, and tax policy more. It is important to note that the policies implemented are the same regardless of whom the initial proposer is in any bargaining round since we have assumed the period of time between bargaining rounds is infinitesimally small so that in equilibrium, after making the appropriate concessions, players are indifferent between being a proposer or a responder.

In order to make the intuition for this clearer, Figure 2 plots the impulse response functions (IRFs) for each of these variables for a shock which raises debt disequilibrium by $10 \%$ with an assumed debt-GDP ratio of 20\%, while Figure 3 replicates the same experiment with a debt-GDP ratio of $80 \%$. There are two lines within each subplot: the red solid line for the case without conflict/bargaining, and a blue dashed line for the policy outcomes with bargaining and a degree of conflict over inflation given by $x=0.2$. Without conflict/bargaining, when steady-state debt levels are relatively low (Figure 2), higher debt results in cuts in government spending and increases in taxation, which raise inflation, but with 

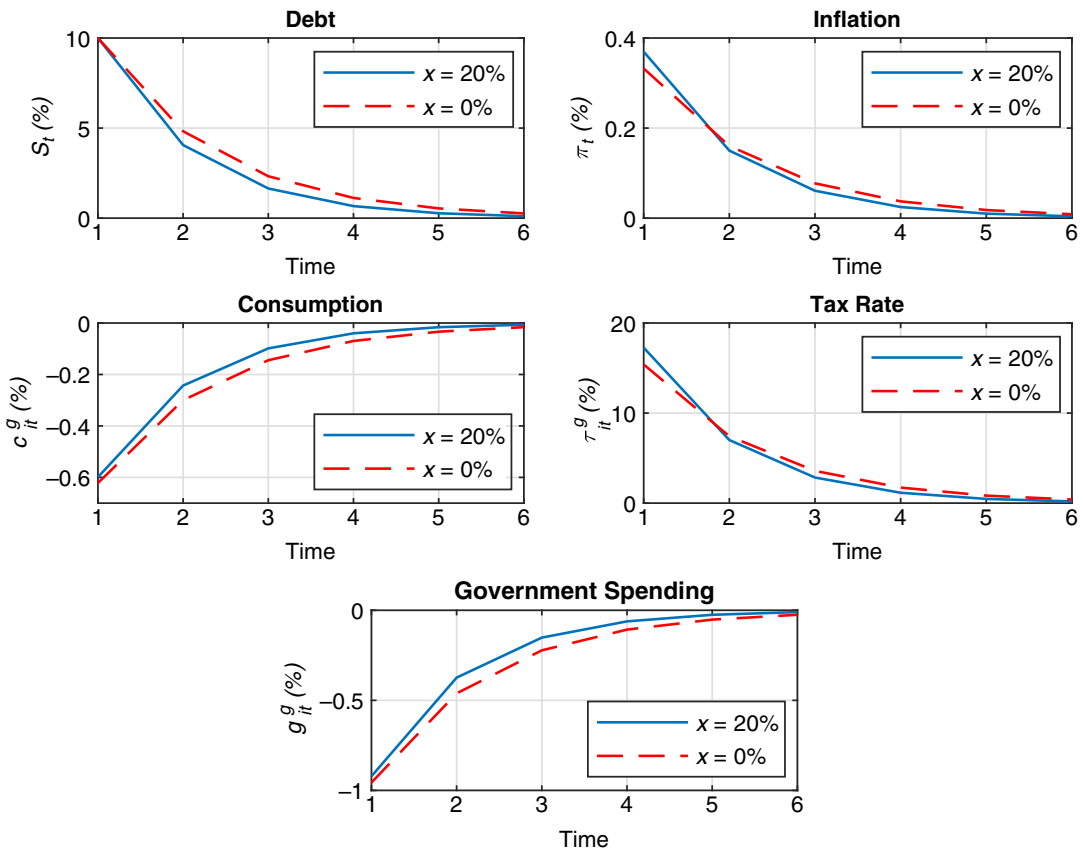

Notes: Impulse response functions to a positive (10\%) debt shock, for a debt-GDP ratio of 20\%, with conflict over inflation stabilization. The red dashed line reflects the case without conflict/bargaining. The solid blue line is the bargained outcome with conflict over inflation stabilization of $x=20 \%$.

FIGURE 2. Inflation conflict and bargaining-low debt.

an offsetting tightening of monetary policy which reduces private consumption. Debt is adjusted gradually, primarily through spending cuts and tax increases. With conflict, the speed of debt stabilization is increased, tax rates are increased, monetary policy is not tightened as aggressively (consumption generally falls by less), and inflation jumps by more. Government spending is also generally not reduced by as much. The initial jump in inflation, tax increases, and moderation in the monetary tightening have successfully reduced debt more aggressively so that disequilibrium in all welfare-relevant variables is less from period 2 onwards.

Figure 3 plots the same IRFs with and without conflict but for a significantly higher steady-state debt-GDP ratio of $80 \%$. In this case, the relaxation in monetary policy and surprise inflation it induces are the primary tools for stabilizing debt, with tax cuts to help stabilize inflation given the substantial monetary accommodation. In the face of political negotiations, the party with less inflation aversion proposes milder spending cuts and less monetary accommodation to obtain the approval of the inflation-averse party who dislikes the higher inflation that emerges. As a result, the main difference in the policy mix, relative to the policy implemented in the absence of conflict, is that the anti-inflation tax cuts are now substantially reduced. 

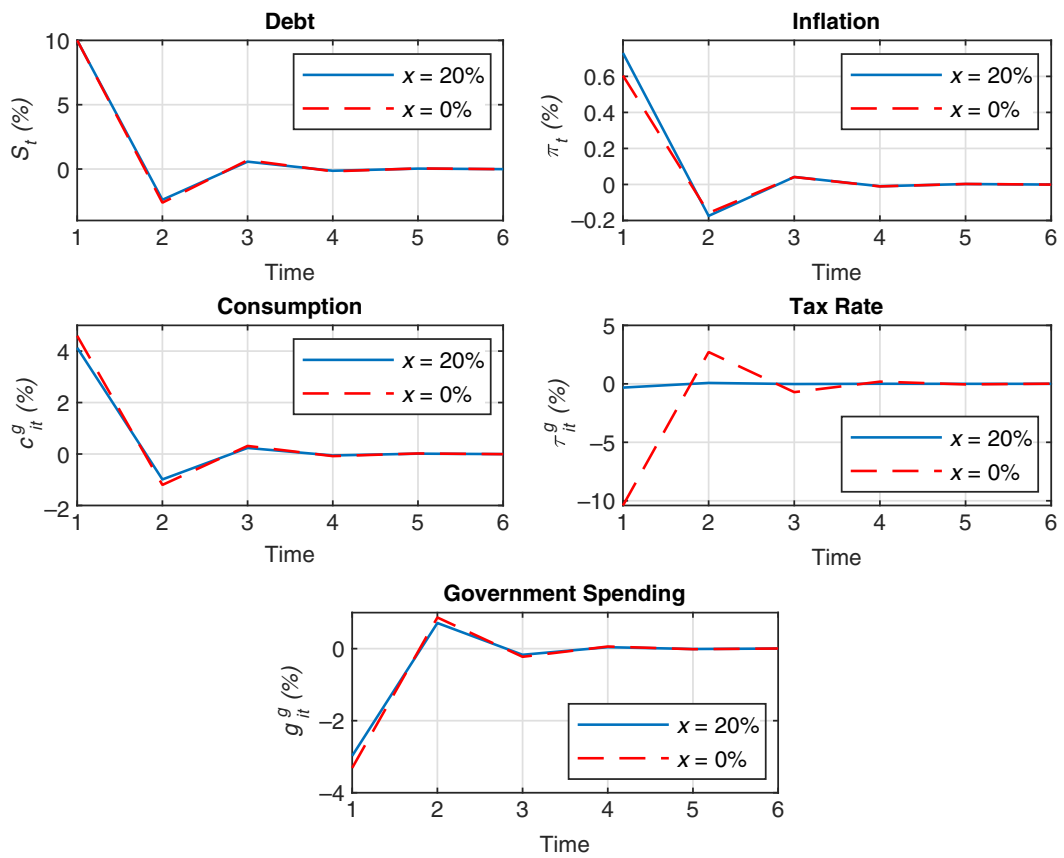

Notes: Impulse response functions to a positive (10\%) debt shock, for a debt-GDP ratio of $80 \%$, with conflict over inflation stabilization. The red dashed line reflects the case without conflict/bargaining. The solid blue line is the bargained outcome with conflict over inflation stabilization of $x=20 \%$.

FIGURE 3. Inflation conflict and bargaining-high debt.

Conflict Over the Use of Monetary Policy. We now turn to the case of conflict over private consumption, see Figure 4. Since fluctuations in private consumption are primarily induced by changes in real interest rates, this conflict can be seen as a proxy for conflict over the use of monetary policy to stabilize government debt. Here the results vary in important ways across different steady-state debt levels. In contrast to the case where conflict was over inflation, at lower debt levels, debt stabilization is slower rather than faster. Essentially, the policy makers agree to use all policy instruments less in stabilizing debt, and this is welfare improving for both policy makers. In effect, the time inconsistency problem has been partially overcome due to the conflict over the use of an accommodative monetary policy and both parties experience the welfare benefits of a more gradual debt reduction. At mid to high debt levels, the coefficient on consumption remains lower in the presence of conflict/bargaining implying that monetary policy is not used to the same extent in the face of such conflict. However, as debt levels rise, the use of other instruments is heightened. At higher debt levels, monetary policy accommodation is one of the most effective ways of stabilizing debt, by introducing a conflict over the use of that instrument there is little compensation the player 

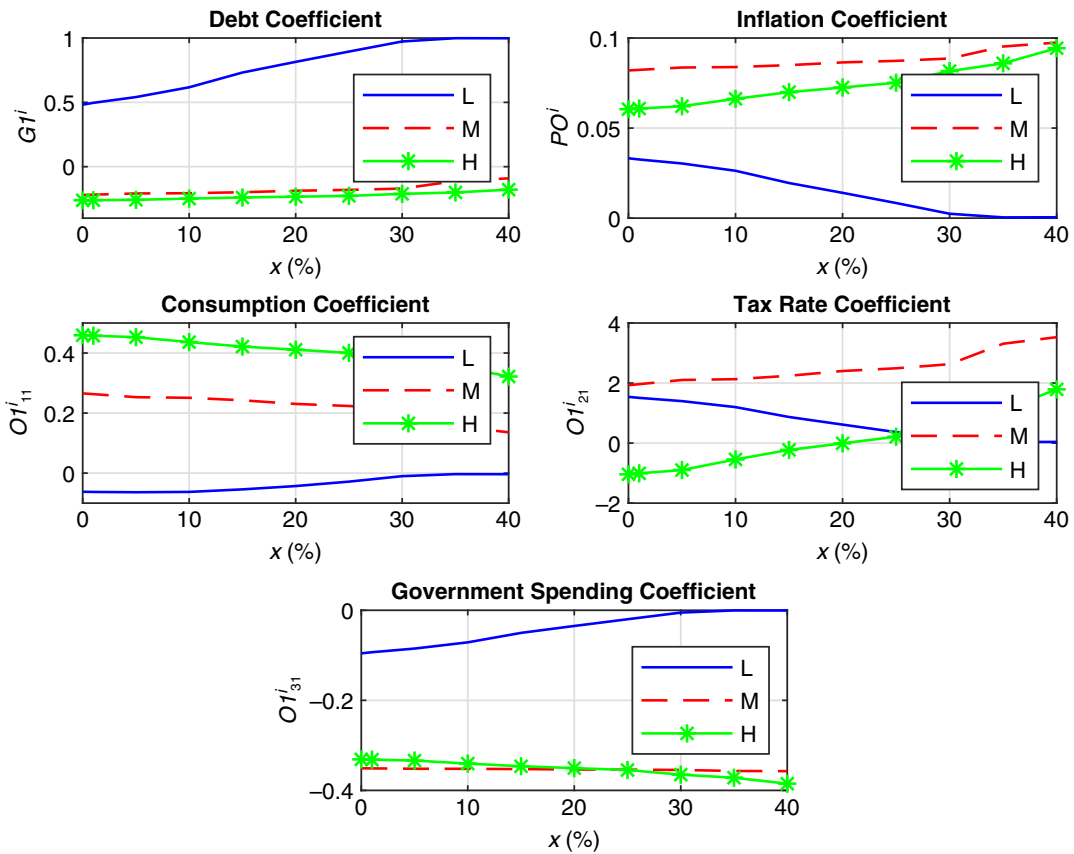

Notes: The figure plots equilibrium coefficients that multiply debt, $b_{t-1}$, against the degree of conflict, $x$, expressed as a percentage. The solid blue line-low debt of $20 \%$ of GDP, red dashed line-medium debt of $50 \%$ of GDP, green circles_-high debt of $80 \%$ of GDP.

FIGURE 4. MPE coefficients and conflict over monetary policy.

with the low aversion to monetary accommodation can offer to induce the other player to agree to use monetary policy in that way.

Figures 5 and 6 provide IRFs at debt levels of $20 \%$ and $80 \%$ of GDP, respectively. Here, at low debt levels, we see the speed of debt stabilization is substantially reduced relative to the benchmark without conflict/bargaining, and the policy mix involves smaller government spending cuts, tax increases, and inflation at the same time as a less anti-inflation monetary policy (private consumption falls by less). At higher debt levels (Figure 6), the need to stabilize debt through other channels, once the use of accommodative monetary policy has been reduced, implies that government spending is cut by more, taxes rise rather than fall, and the initial inflation surprise is greater.

Our final form of conflict is over government spending (see Figure 7). In this case, we get a mixture of the trade-offs found under the other two forms of conflict. At low to medium debt levels, the player with the lower costs of using spending cuts as the fiscal consolidation tool succeeds in implementing such a policy by proposing a policy mix which reduces inflation, primarily by moderating tax increases. This is sufficient to achieve consensus over the implemented policy. However, at higher debt levels, the ease of stabilizing debt through surprise 

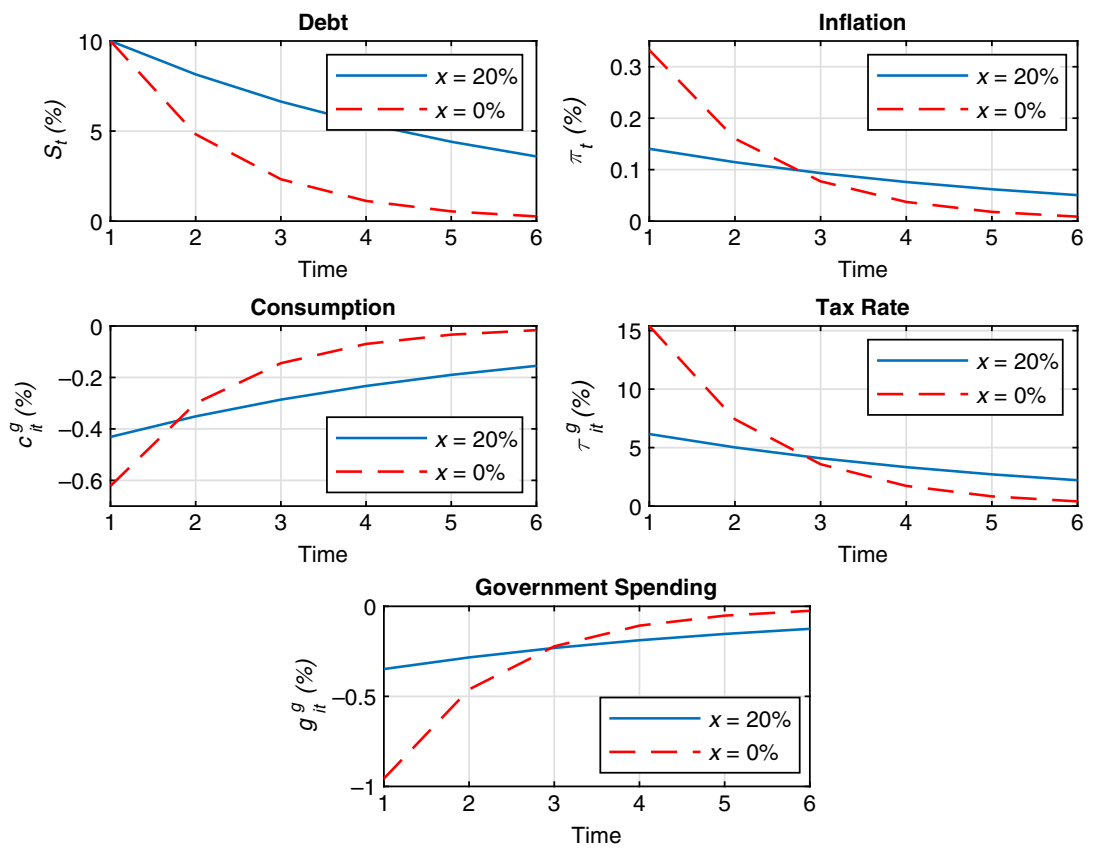

Notes: Impulse response functions to a positive (10\%) debt shock, for a debt-GDP ratio of 20\%, with conflict over the consumption gap-the de facto instrument of monetary policy. The red dashed line reflects the case without conflict/bargaining. The solid blue line is the bargained outcome with conflict over inflation stabilization of $x=20 \%$.

FIGURE 5. Monetary policy conflict and bargaining-low debt.

inflation and monetary accommodation means that it is no longer viable for the player less averse to fluctuations in government spending to obtain agreement by making a proposal which reduces the reliance on such policies- the resultant fluctuations in government spending needed to stabilize debt are simply too costly for his opponent. Therefore, we move to a situation which is more like conflict over the degree of consumption stabilization - the player averse to such fluctuations dominates the bargaining and reduces their use.

Figure 8 plots the paths for government spending under the bargained policy as well as the benchmark of no conflict/bargaining. ${ }^{24}$ When debt levels are low, the bargained outcome implies larger spending cuts (larger than in the case of no conflict) in order to minimize the size of the consumption gap and reduce equilibrium inflation as a means of obtaining the agreement of the player more adverse to fluctuations in government spending. At higher steady-state debt levels, the reduced use of government spending in achieving the fiscal consolidation is in line with the preferences of the party averse to fluctuations in government spending, and since this instrument is not used heavily at higher debt levels, even without bargaining, there is only a minor adjustment to all other policy instruments when stabilizing debt. 

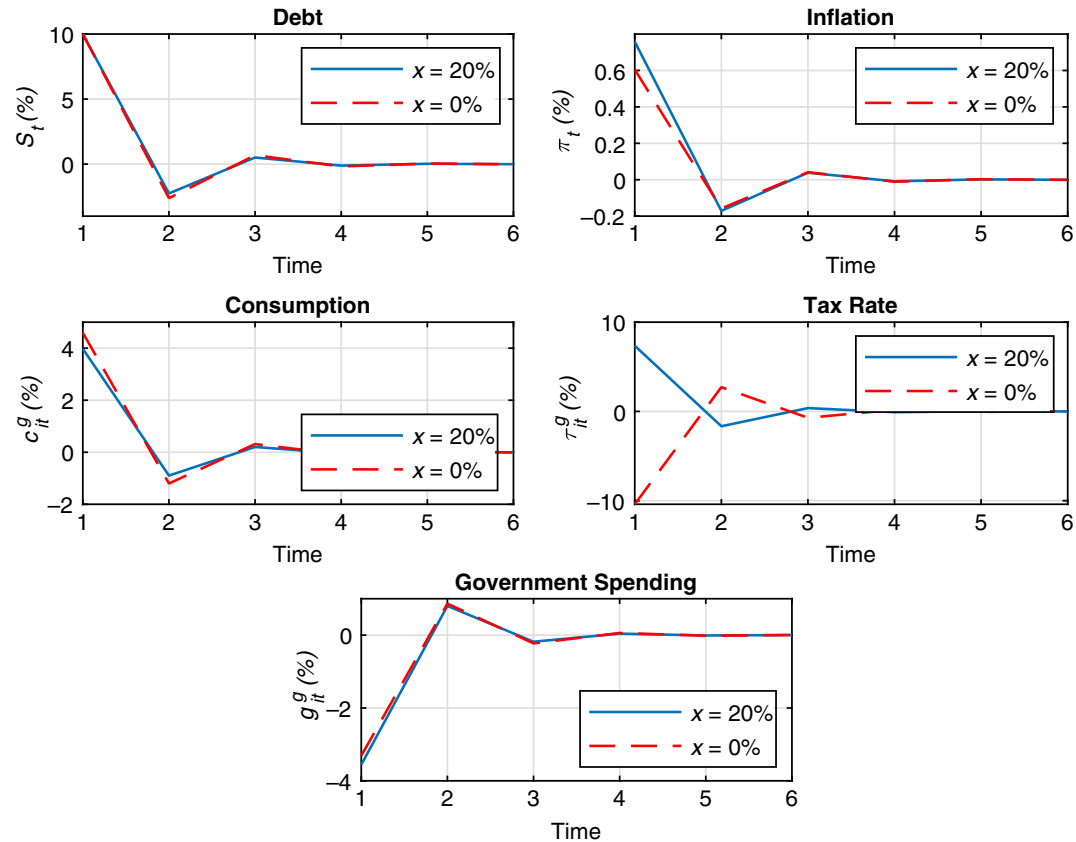

Notes: Impulse response functions to a positive (10\%) debt shock, for a debt-GDP ratio of $80 \%$, with conflict over the consumption gap-the de facto instrument of monetary policy. The red dashed line reflects the case without conflict/bargaining. The solid blue line is the bargained outcome with conflict over inflation stabilization of $x=20 \%$.

FIGURE 6. Monetary policy conflict and bargaining—high debt.

\section{EXTENSION I: A CONSERVATIVE CENTRAL BANK}

In this section, we extend our results by assuming that the political parties interact with an independent $\mathrm{CB}$, which controls the short-term interest rate and may be more conservative than society, in the sense that it places a greater weight on inflation than found in the social welfare function, following the arguments in Rogoff (1985). It will be shown that outcomes achieved through bargaining with an independent $\mathrm{CB}$ are quite different from those which emerge when the interactions are strategic. This is due to the fact that bargained outcomes require both parties to anticipate the costs of alternative policies for their opponent which is not the case in traditional models of strategic interaction between policy makers.

The objective functions for the two political parties remain the same in the previous section. With focus on conflict on government spending, these become

$$
\begin{aligned}
\Gamma^{i}= & -\bar{N}^{1+\varphi} \frac{1}{2} E_{0} \sum_{t=0}^{\infty} \beta^{t} l(1,1+x, 1,1)+t i p+O[2] \text { with } \\
l(1,1+x, 1,1)= & \sigma \theta\left(\widehat{C}_{t}-\widehat{C}_{t}^{*}\right)^{2}+(1+x) \sigma(1-\theta)\left(\widehat{G}_{t}-\widehat{G}_{t}^{*}\right)^{2} \\
& +\varphi\left(\widehat{Y}_{t}-\widehat{Y}_{t}^{*}\right)^{2}+\frac{\epsilon}{\gamma} \pi_{t}^{2},
\end{aligned}
$$



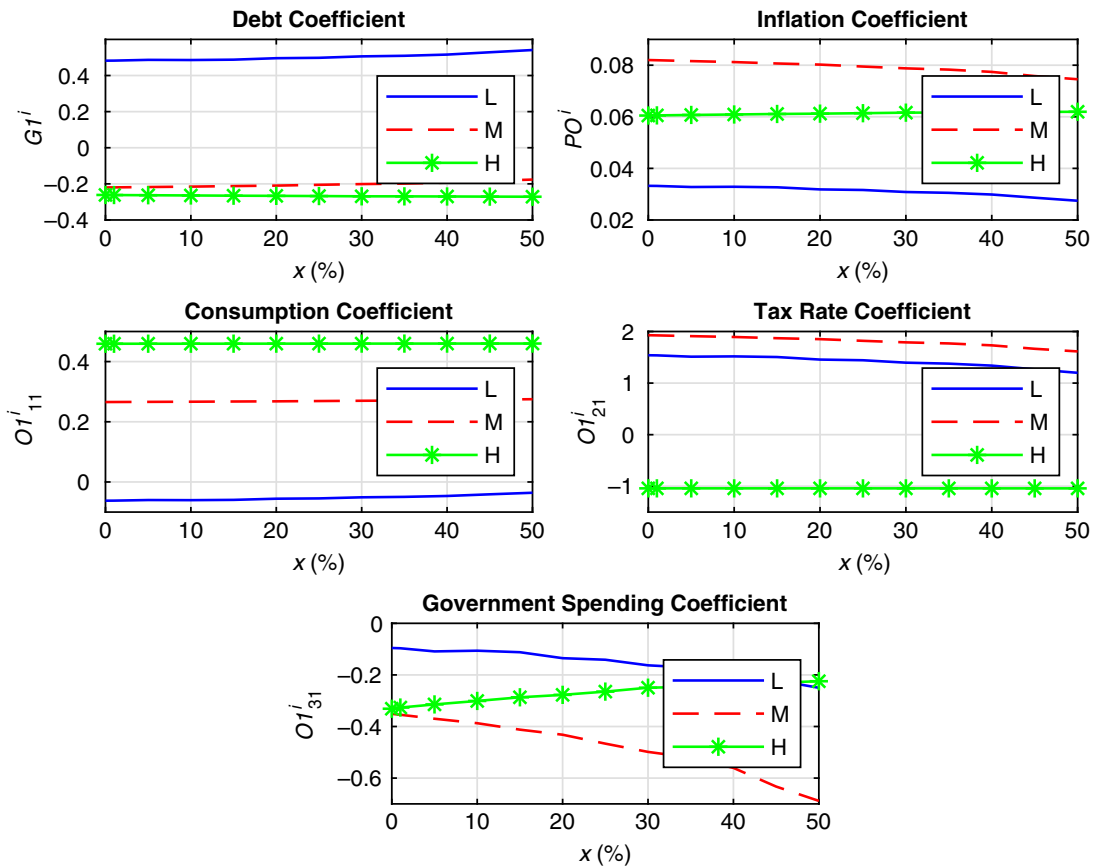

Notes: The figure plots equilibrium coefficients that multiply debt, $b_{t-1}$, against the degree of conflict, $x$, expressed as a percentage. The solid blue line-low debt of $20 \%$ of GDP, red dashed line-medium debt of $50 \%$ of GDP, green circles-high debt of $80 \%$ of GDP.

FIGURE 7. MPE coefficients and conflict over public consumption.

and

$$
\begin{aligned}
\Gamma^{j}= & -\bar{N}^{1+\varphi} \frac{1}{2} E_{0} \sum_{t=0}^{\infty} \beta^{t} l(1,1-x, 1,1)+t i p+O[2] \text { with } \\
l(1,1-x, 1,1)= & \sigma \theta\left(\widehat{C}_{t}-\widehat{C}_{t}^{*}\right)^{2}+(1-x) \sigma(1-\theta)\left(\widehat{G}_{t}-\widehat{G}_{t}^{*}\right)^{2} \\
& +\varphi\left(\widehat{Y}_{t}-\widehat{Y}_{t}^{*}\right)^{2}+\frac{\epsilon}{\gamma} \pi_{t}^{2},
\end{aligned}
$$

However, their controls now reduce to

$$
\mathbf{u}_{i t}=\left[\begin{array}{c}
\tau_{i t}^{g} \\
g_{i t}^{g}
\end{array}\right],
$$

and they take the CB's policies (as reflected in $c_{t}^{g}$ ) as given. Instead, the objective function for the $\mathrm{CB}$ is as follows

$$
\begin{aligned}
\Gamma^{C B}= & -\bar{N}^{1+\varphi} \frac{1}{2} E_{0} \sum_{t=0}^{\infty} \beta^{t} l\left(1,1,1,1+x^{C B}\right)+t i p+O[2] \text { with } \\
l\left(1,1,1,1+x^{C B}\right)= & \sigma \theta\left(\widehat{C}_{t}-\widehat{C}_{t}^{*}\right)^{2}+\sigma(1-\theta)\left(\widehat{G}_{t}-\widehat{G}_{t}^{*}\right)^{2} \\
& +\varphi\left(\widehat{Y}_{t}-\widehat{Y}_{t}^{*}\right)^{2}+\left(1+x^{C B}\right) \frac{\epsilon}{\gamma} \pi_{t}^{2},
\end{aligned}
$$


(a)

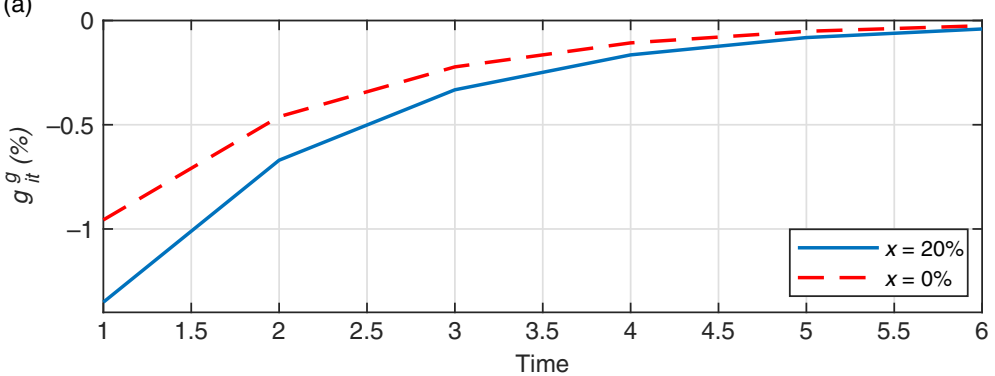

(b)

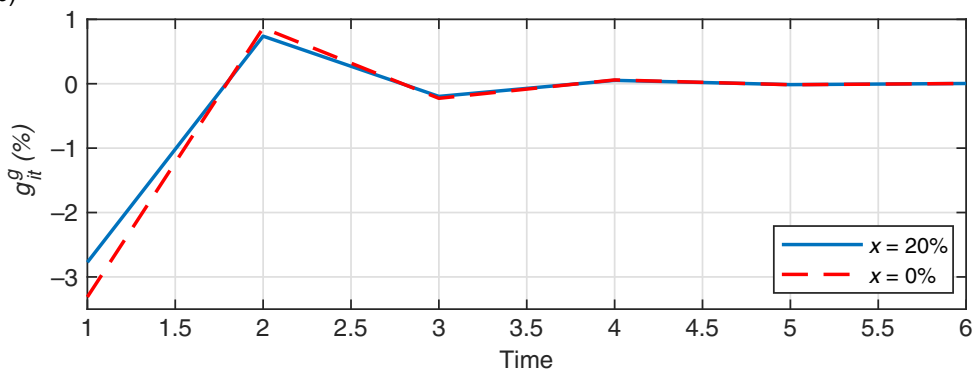

Notes: Impulse response functions to a positive (10\%) debt shock, for a debt-GDP ratio of $20 \%$ and $80 \%$, with conflict over the public consumption gap. The red dashed line reflects the case without conflict/bargaining. The solid blue line is the bargained outcome with conflict over government spending stabilization of $x=20 \%$.

FIGURE 8. Government consumption conflict and bargaining. (a) Low steady-state debtGDP ratio (20\%). (b) High steady-state debt-GDP ratio (80\%).

with the political parties' policy instruments (47) taken as given. The following proposition summarizes the equilibrium for this game.

PROPOSITION 2. For $\delta \rightarrow 1$, the MPE policies are linear in the state $\mathbf{S}_{t}$ :

$$
\begin{aligned}
\mathbf{u}_{i t} & =\mathbf{O 1}{ }_{B}^{i} \mathbf{S}_{t-1}, \\
c_{t}^{g} & =\mathbf{O 1} 1_{C B}^{i} \mathbf{S}_{t-1},
\end{aligned}
$$

with

$$
\boldsymbol{\mu}^{j}=\delta \boldsymbol{\Phi}^{j}
$$

where the payoff coefficients are

$$
\begin{aligned}
\boldsymbol{\Phi}^{i}= & \mathbf{P} \mathbf{0}_{C B}^{i^{\prime}} \mathbf{R}^{i} \mathbf{P} \mathbf{0}_{C B}^{i}+\mathbf{O} 1_{C B}^{i \prime} \mathbf{Q}_{1}^{i} \mathbf{O} 1_{C B}^{i}+\mathbf{O} 1_{B}^{i \prime} \mathbf{Q}_{2}^{i} \mathbf{O} 1_{B}^{i} \\
& +\mathbf{O} 1_{C B}^{i \prime} \mathbf{Q}_{3}^{i} \mathbf{O} 1_{B}^{i}+\beta \mathbf{G} \mathbf{1}_{C B}^{i} \boldsymbol{\beta}^{i} \mathbf{G} \mathbf{1}_{C B}^{i}, \\
\boldsymbol{\mu}^{j}= & \mathbf{P} \mathbf{0}_{C B}^{i^{\prime}} \mathbf{R}^{j} \mathbf{P} \mathbf{0}_{C B}^{i}+\mathbf{O} 1_{C B}^{i \prime} \mathbf{Q}_{1}^{j} \mathbf{O} 1_{C B}^{i}+\mathbf{O} 1_{B}^{i \prime} \mathbf{Q}_{2}^{j} \mathbf{O} 1_{B}^{i} \\
& +\mathbf{O} 1_{C B}^{i \prime} \mathbf{Q}_{3}^{j} \mathbf{O} 1_{B}^{i}+\beta \mathbf{G} \mathbf{1}_{C B}^{i \prime} \boldsymbol{\beta}^{j} \mathbf{G} \mathbf{1}_{C B}^{i},
\end{aligned}
$$




$$
\begin{gathered}
\boldsymbol{\Phi}_{\mathbf{i}}^{C B}=\mathbf{P} \mathbf{0}_{C B}^{i^{\prime}} \mathbf{R}^{C} \mathbf{P} \mathbf{0}_{C B}^{i}+\mathbf{O} \mathbf{1}_{C B}^{i \prime} \mathbf{Q}_{1}^{C} \mathbf{O} \mathbf{1}_{C B}^{i}+\mathbf{O} \mathbf{1}_{B}^{i \prime} \mathbf{Q}_{2}^{C} \mathbf{O} \mathbf{1}_{B}^{i} \\
+\mathbf{O} \mathbf{1}_{C B}^{i \prime} \mathbf{Q}_{3}^{C} \mathbf{O} \mathbf{1}_{B}^{i}+\beta \mathbf{G} \mathbf{1}_{C B}^{i \prime} \boldsymbol{\beta}^{C} \mathbf{G} \mathbf{1}_{C B}^{i}, \\
\boldsymbol{\beta}^{i}=q^{i} \boldsymbol{\Phi}^{i}+\left(1-q^{i}\right) \boldsymbol{\mu}^{i},
\end{gathered}
$$

the forecast coefficients are

$$
\begin{aligned}
& f=q^{i} \mathbf{P} \mathbf{0}_{C B}^{i}+\left(1-q^{i}\right) \mathbf{P} \mathbf{0}_{C B}^{j}, \\
& c=q^{i} \mathbf{O} \mathbf{1}_{C B}^{i}+\left(1-q^{i}\right) \mathbf{O} 1_{C B}^{j},
\end{aligned}
$$

and $\mathbf{O} \mathbf{1}_{B}^{i}, \mathbf{O 1}{ }_{C B}^{i}, \mathbf{P} \mathbf{0}_{C B}^{i}, \mathbf{G 1}_{C B}^{i}$ are defined in (C16)-(C19) in Appendix $C$, with $i, j=$ 1,2 , and $i \neq j$.

Proof. The proof follows an argument similar to the one for Proposition 1, see Appendix C.

We next show the implications of introducing an independent $\mathrm{CB}$ for the numerical analysis. Figure 9 considers the case of an independent $\mathrm{CB}$ with varying degrees of inflation aversion $\left(x^{C B}\right.$, in percentage, is equal to $\left.0,25,50 \%\right)$, setting monetary policy conditional on the bargained outcome of the policy game between two fiscal authorities with different attitudes to the use of government consumption as a policy instrument ( $x$, in percentage, is equal to $20 \%$ ). As the degree of inflation conservatism rises, the CB tightens monetary policy for a given fiscal shock, leading to a larger fall in private consumption. This moderates the initial jump in inflation. Therefore, an independent CB's inflation conservatism reduces the level of inflation associated with a given level of debt. The fact that the inflationary costs of debt are lower, for a given level of debt, thanks to the credibility of the $\mathrm{CB}$, means that the fiscal players have less incentive to reduce debt rapidly following a fiscal shock. As a result, their bargained fiscal policy mix implies a slower pace of fiscal correction and less aggressive use of both taxes and government consumption as a result.

The outcomes in this case are quite different from those seen when policy emerged as a result of bargaining between two players with different attitudes to inflation, see Figure 2. In the case of conflict, the less inflation-averse player was typically able to extract greater concessions from the other player due to the efficacy of using inflation as a debt stabilization device, ceteris paribus. As a result, greater inflation conflict tended to increase inflation for a given debt level and raise the speed of fiscal correction. This reflects the fact that under bargaining policy outcomes are influenced by the costs and benefits experienced by each player as they seek an agreement. A truly independent CB, on the other hand, does not care how costly their policy choices are for the government, except to the extent that it affects their policy response, and as a result inflation is lower in the case of strategic interactions between the fiscal authorities and the independent CB. 

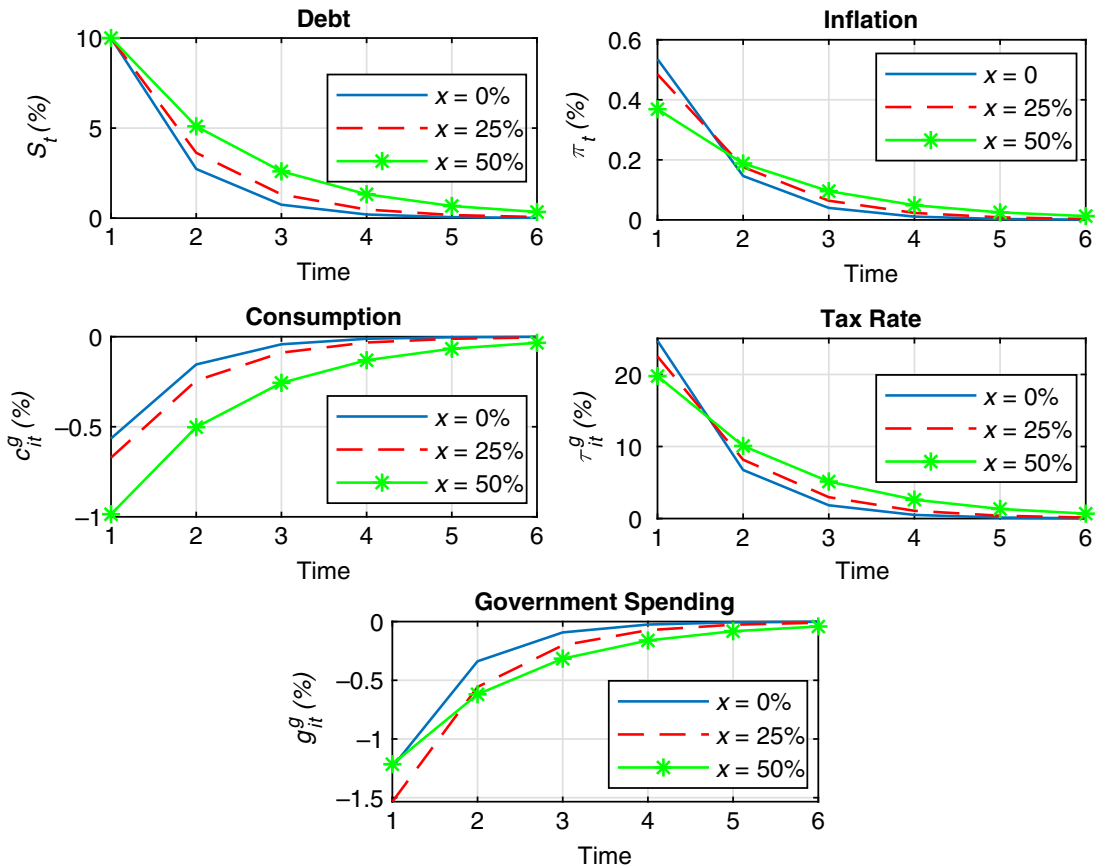

Notes: Impulse response functions for a positive (10\%) debt shock, for debt-GDP ratio of $25 \%$, with conflict both over government spending gap stabilization $\left(x^{g}\right.$ (in percentage) $\left.=20 \%\right)$ and inflation stabilization (for fiscal players, $x_{i}^{\pi}=100 \%$, for any $i=1,2$ and for CB, $x_{C B}^{\pi}=100+x$ ). Solid blue line — central bank preferences mirror social welfare, $x=0 \%$; red dashed line—inflation-averse central bank, $x=25 \%$; and green circles-inflation-averse central bank, $x=50 \%$.

FIGURE 9. Fiscal bargaining and an independent central bank.

\section{EXTENSION II: NON-SEPARABLE UTILITY}

The benchmark model assumed that private and public consumption were separable in agent's utility. This extension relaxes this assumption by following D'Auria (2015) in assuming that the private and public consumption can be complements/substitutes. Specifically, we assume that utility function is now given by

$$
E_{0} \sum_{t=0}^{\infty} \beta^{t}\left(\frac{\widetilde{C}_{t}^{1-\sigma} \xi_{t}^{-\sigma}}{1-\sigma}+\chi \frac{G_{t}^{1-\sigma} \xi_{t}^{-\sigma}}{1-\sigma}-\frac{N_{t}^{1+\varphi} \xi_{t}^{-\sigma} \xi_{t}^{N}}{1+\varphi}\right),
$$

where $\widetilde{C}_{t}=C_{t}+v G_{t}$ such that $v<(>) 0$ implies private and public consumption are complements (substitutes). Note that we need to retain the separable element of government consumption in utility, $\chi \frac{G_{t}^{1-\sigma} \xi_{t}^{-\sigma}}{1-\sigma}$, to ensure that the marginal utility of government consumption does not turn negative when private and public consumption are complements, $v<0$. We return to our benchmark specification when $v=0$. 
The introduction of non-separable preferences implies the consumption Euler equation is now defined in terms of this adjusted measure of consumption, $\widetilde{C}_{t}$,

$$
\beta R_{t} E_{t}\left[\left(\frac{\widetilde{C}_{t}}{\widetilde{C}_{t+1}}\right)^{\sigma}\left(\frac{\xi_{t}}{\xi_{t+1}}\right)^{\sigma}\left(\frac{P_{t}}{P_{t+1}}\right)\right]=1 .
$$

Similarly for the labor supply, decision depends on the marginal utility of private consumption adjusted for public consumption,

$$
\left(1-\tau_{t}\right) w_{t}=N_{t}^{\varphi} \widetilde{C}_{t}^{\sigma} \xi_{t}^{N}
$$

While the goods market clearing condition remains

$$
\begin{aligned}
Y_{t} & =C_{t}+G_{t} \\
& =\widetilde{C}_{t}+(1-v) G_{t} .
\end{aligned}
$$

Appendix D shows how this affects the log-linearized economy, its steadystate, and our second-order approximation to social welfare. In essence, the policy problem remains isomorphic to the benchmark model, but where the consumption gap is now defined as $c_{t}^{v}=\widehat{\widetilde{C}}_{t}-\widehat{\widetilde{C}}_{t}^{*}$ and parameter $\theta^{\prime}=\frac{\widetilde{\widetilde{C}}}{\bar{Y}}$ now defines the share of adjusted consumption in GDP, such that $\frac{\bar{G}}{\bar{Y}}=\frac{1-\theta^{\prime}}{1-v}$. To obtain the implied path for consumption, we use the fact that the log-linearized definition of adjusted consumption is given by

$$
\widehat{\widetilde{C}}_{t}=\frac{\bar{C}}{\underset{\widetilde{C}}{\bar{C}}} \widehat{C}_{t}+v \underset{\overline{\widetilde{G}}}{\stackrel{\bar{C}}{\bar{G}}} \widehat{G}_{t}
$$

Since our steady state is assumed to be efficient, the steady-state ratios of private and public consumption to adjusted consumption can be tied down to obtain the log-linear relationship

$$
\widehat{C}_{t}=\left(1-v\left(\frac{\chi}{1-v}\right)^{\frac{1}{\sigma}}\right)^{-1} \widehat{\widetilde{C}}_{t}-v\left(\left(\frac{\chi}{1-v}\right)^{-\frac{1}{\sigma}}-v\right)^{-1} \widehat{G}_{t} .
$$

The values of $v$ in the literature cover both cases of substitutes (see, e.g., Aschauer (1985) who obtains estimates ranging from 0.23 to 0.42 for the USA) and complements (Karras (1994) estimates that the $v<0$ for a majority of the 30 OECD economies he considers. Similarly, Leeper et al. (2017) considers a range of estimates lying between -1.58 and +1.58 . Figure 10 adopts values for $v$ of \pm 0.23 . Since government consumption is chosen optimally in our model, rather than considered to be an exogenous process, we adjust the parameter $\chi$ when varying $v$ in order to ensure the steady-state $\mathrm{G} / \mathrm{Y}$ ratio remains at its calibrated value of $0.25{ }^{25}$

The impact of this when conflict is over government consumption (at 20\%) is shown in Figure 10. Given the level of debt, when $v=0$, we obtain a pattern of response like that described in Figure 5. The bargained policy outcome cuts government consumption, tightens monetary policy (leading to a fall in private 

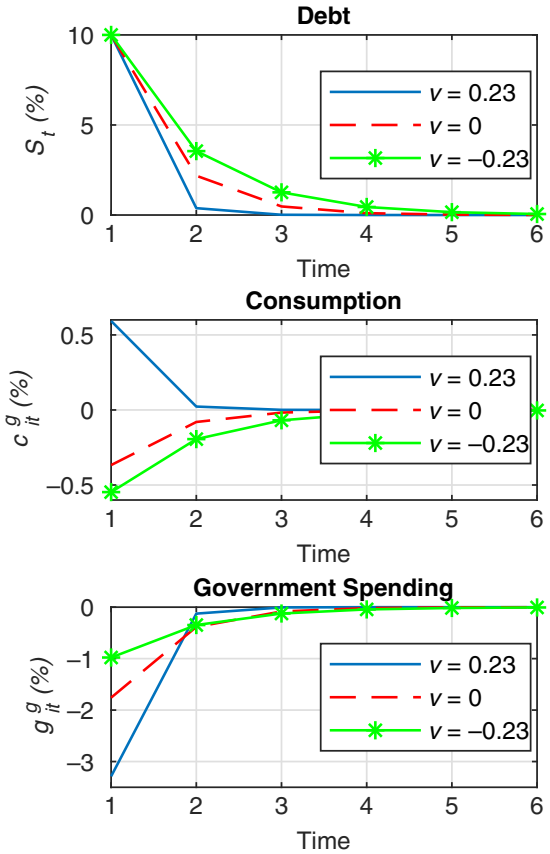
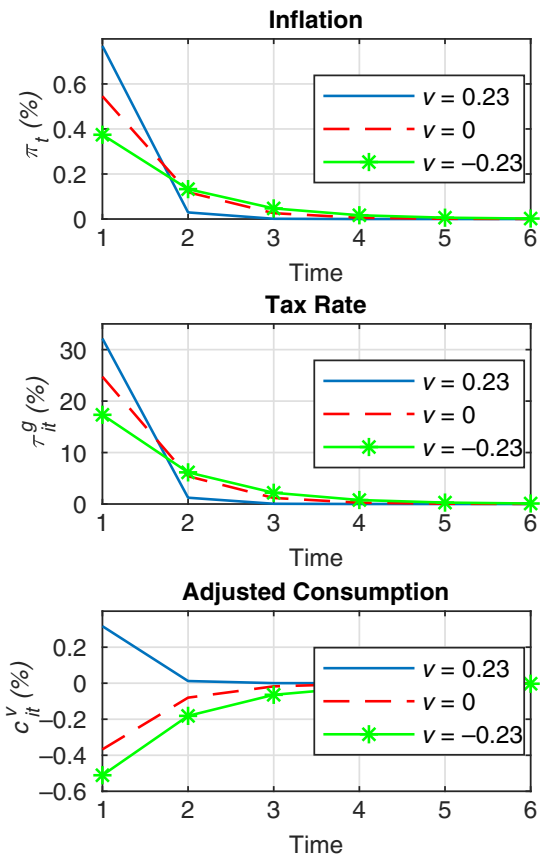

Notes: Impulse response functions for a positive (10\%) debt shock, for debt-GDP ratio of 25\%, with conflict over government spending gap stabilization $\left(x^{g}\right.$ (in percentage $)=20 \%$ ) with different degrees of substitutability between private and public consumption in utility, $u\left(C_{t}+v G_{t}\right)$. Solid blue line$v=0.23$ (private and public consumption are substitutes); red dashed line $-v=0$ (separable utility); and $v=-0.23$ (private and public consumption are complements).

FIGURE 10. Conflict over public consumption and non-separable utility.

consumption), and raises taxes to reduce the debt burden. Introducing complementarity between public and private consumption, $v=-0.23$, means that the cut in government consumption reduces the marginal utility of consumption, cet. par., encouraging households to reduce private consumption. In order to mitigate this effect, bargained policy moderates the fall in public consumption. The bargained policy also reduces the increase in taxation. This slows, significantly, the pace of debt reduction.

The opposite case of substitutability between private and public consumption, $v>0$, means that the fall in public consumption actually raises the marginal utility of private consumption encouraging the players to agree to relax monetary policy and raise private consumption. In combination with a significant increase in taxation, this stabilizes debt more quickly relative to the benchmark and case of complementarity between private and public consumption.

\section{CONCLUSIONS}

In this paper, we examined the effects of bargaining over policy choices between different policy makers in a New Keynesian DSGE model. Since the bargaining 
takes place in the context of a New Keynesian model with one monetary and two fiscal policy instruments, the process of reaching agreement can give rise to a policy mix which differs significantly from that obtained when policy is implemented by a single policy maker. Which policy maker was able to get closest to their preferred policy mix depends crucially on which instrument/element of social welfare the policy makers were in conflict over. Moreover, the level of steady-state debt affects the outcome of the negotiations.

For example, at low debt levels, the policy maker less concerned with avoiding fluctuations in government spending can induce his opponent to accept more significant cuts in public consumption as part of a consolidation effort since he can offer other changes in the policy mix which make the policy more palatable. At higher debt levels, where spending cuts are relatively less effective than other policy instruments in stabilizing debt, the bargained outcome reduces the reliance on spending cuts to stabilize the debt. While conflict over the importance of reducing volatility in the consumption gap leads to a bargained policy mix which reduces that volatility, a similar conflict over the merits of inflation stabilization increases the use of surprise inflation as a debt stabilization tool. In other words, the implications of bargaining across a whole policy mix in an environment subject to a significant time inconsistency problem give rise to policy outcomes which are significantly different to those implemented by a single policy with preferences equal to the average of the two players.

Extending the model to include an independent $\mathrm{CB}$, which sets monetary policy taking the fiscal policy implemented by two fiscal players as given, implies quite different policy outcomes to the case where a CB bargains with a fiscal authority. A truly independent $\mathrm{CB}$ sets their policy instruments to maximize their delegated welfare, without caring about the implications of that policy for the government, except to the extent that it affects the government's fiscal policy stance. This implies an aggressive use of monetary policy to reduce the inflationary consequences of fiscal shocks and results in the fiscal players agreeing a slower speed of fiscal correction. An inflation-averse CB which, instead, bargains with the government over the setting of macroeconomic policies agrees to relax monetary policy to help stabilize debt in return for concessions over other aspects of the policy mix. It is therefore important to assess the degree to which $\mathrm{CBs}$ are independent-do they set policy regardless of the consequences for the government's welfare or do they reach an implicit bargain with the government when setting policy?

\section{NOTES}

1. Influential examples include Benigno and Woodford (2004) and Schmitt-Grohe and Uribe (2004).

2. In the context of sticky price models, time-consistent monetary and fiscal policy is analyzed in, for example, Niemann and Pilcher (2011), Leith and Wren-Lewis (2013), Niemann et al. (2013b), Leeper et al. (2016), and Leeper and Leith (2016). Additionally, starting with Lucas and Stokey (1983), there are numerous papers exploring the time consistency of fiscal policy in the context of flexible price 
economies subject to monetary frictions (see, e.g., Obstfeld (1991, 1997), Nicolini (1998), Ellison and Rankin (2007), Diaz-Giminez et al. (2008), Martin (2009), and Aiyagari et al. (2002)).

3. A classic reference for this approach is Currie and Levine (1993), while recent examples include Niemann and Pilcher (2011), Niemann et al. (2013a), Adam and Billi (2014), Chen et al. (2017), and Bai et al. (2017).

4. We are able to sustain a wide range of interpretations of the nature of the conflict as the bargaining process determines the agreed equilibrium policy mix of available monetary and fiscal instruments, but does not require any particular distribution of control of policy instruments across players. Therefore, it does not matter whether the agreed policy is implemented by individual government ministries, different branches of the legislature or distinct monetary and fiscal authorities, etc. What is important is that the overall policy mix is determined by a process of bargaining, which is not affected by the identity of who implements the agreed policy. In essence, our players represent different sources of influence over the policy-making process rather than the technicians implementing policy.

5. In section 6, we augment our model to include an independent central bank interacting strategically alongside two political players who bargain over the fiscal policy mix. This enables us to contrast our approach with the more conventional one.

6. Conflict over the desirability of stabilizing the consumption gap serves as a proxy for conflict over the use of monetary policy in stabilizing debt, since fluctuations in consumption are due to movements in real interest rates in our New Keynesian economy.

7. The war of attrition literature, typically, does not allow for bargaining between coalition partners. Instead, due to asymmetric information over the costs each faces under a given consolidation plan, coalition partners slowly edge toward agreement as they try to obtain information about the other's cost function. Notable exceptions are Hsieh (2000), Sibert and Perraudin (2000), and Katayama (2008) where bargaining over the burden of consolidation facilitates the extraction of information about the costs the other player faces.

8. Leith and Wren-Lewis (2013) discusses alternative motivations for considering an efficient steady state without recourse to subsidies financed by lump-sum taxes: for example, contemporaneous consumption externalities which offset distortionary taxes (Levine et al. (2008)), an ability to commit to the steady state of a Ramsey problem, but not to how the economy responds to shocks (Levine and Pearlman (2011)) or through a tax on leisure rather than work (Bilbiie et al. (2008)). Our basic policy problem is unaffected by the choice of device used to render the steady-state efficient.

9. For reasons of tractability, all shocks are assumed to be iid. This eliminates the need to track an additional state variable for each shock when solving the bargaining problem.

10. If we considered the lump-sum financed subsidy to be a policy instrument, which could be varied over time, then there would be no trade-off between fiscal solvency and business cycle stabilization, and the policy problem would be rendered trivial.

11. It should be noted that we could define the tax "gap" as being the actual tax rate relative to any benchmark tax rate we choose, such as, for example, the initial steady-state tax rate. However, it is convenient to define the gap relative to the tax rate which offsets the impact of a cost-push shock on inflation.

12. The monetary policy instrument is actually the short-term interest rate. However, the monetary authorities effectively have control over consumption through the consumption Euler equation. Therefore, we treat consumption as being their de facto policy instrument. Note that by substituting the consumption Euler equation into the government's budget constraint, the debt service costs of varying interest rates are fully accounted for.

13. We employ a rational expectation framework, where economic agents have full information on the structure of the game, including players' preferences, and anticipate the state-dependent outcome of the game when forming their expectations.

14. In equilibrium, policies are implemented without delay and the focus is on bargaining frictions which disappear, see (40)-(41) and Appendix B.

15. Our solution allows for preferences to differ across all elements of welfare. However, in the numerical section, we focus on the effects of players attaching different weights to individual elements of social welfare. 
16. We solve the bargaining problem following a noncooperative approach. While both cooperative and noncooperative approaches can give the same solution for the case of a single surplus, when a counteroffer can be made after an infinitesimally short interval of time (Binmore (1987)), in dynamic bargaining (with many agreements still to be achieved), a similar mapping between the two approaches has not yet been established.

17. The expectation is conditional on $i$ being the proposer at time $t$. However, this is omitted in the notation since it is captured by $\mathbf{S}_{t}$, see (23).

18. This can be shown formally following arguments similar to the ones presented in Muthoo (1995) for the case of repeated games.

19. In our framework, delays could be profitable if debt decreases while parties are hagglingwe rule out this case. In other bargaining frameworks, strategic delays can be sustained in equilibrium when uncertainty can be partially solved by waiting (e.g., see Admati and Perry (1987)) or in complete information games when one party bargain with two or more other parties (e.g., see Cai (2000)).

20. There are macroeconomic models (without bargaining) where delays are rational. For instance, Orphanides (1996) shows that, in a stochastic environment, a government facing high inflation should delay its stabilization program for more favorable external conditions.

21. There is no linear term in (36) and (37), because the second-order approximation to utility contains only second-order terms, due to the assumed efficiency of the steady state and the policy makers' preferences are assumed to take the same form.

22. As a result, the value of the per-bargaining-round disagreement, $(1-\delta) X$, does not play a direct role in the numerical solutions, since it will satisfy the acceptance condition (B21) for any $X<0$ when $\delta \rightarrow 1$.

23. In Section 6, we consider the case of an independent central bank which does not bargain over policy with a fiscal authority, but nevertheless sets policy taking account of the setting of fiscal policy.

24. We do not report IRFs for all variables in this case as, for most variables, the differences due to this source of conflict are relatively small. However, the major difference is that government spending cuts are higher (lower) than the non-conflict benchmark at low (high) debt levels, see Figure 7.

25. This implies that $\chi=(1-v)\left(\left(\frac{\bar{G}}{\bar{Y}}\right)^{-1}-(1-v)\right)^{-\sigma}$.

26. When counteroffers tend to be costless, parties make concessions (hence $\lambda_{i}>0$ and $\boldsymbol{\mu}^{j}=\delta \boldsymbol{\Phi}^{j}$ ), as also confirmed in our numerical analysis.

\section{REFERENCES}

Adam, K. and R. M. Billi (2014) Distortionary fiscal policy and monetary policy goals. Economics Letters, Elsevier, 122(1), 1-6.

Admati, A. R. and M. Perry (1987) Strategic delay in bargaining. Review of Economic Studies 54, $345-364$.

Aiyagari, S. R., A. Marcet, T. J. Sargent and J. Seppala (2002) Optimal taxation without statecontingent debt. Journal of Political Economy 110(6), 1220-1254.

Alesina, A. and A. Drazen (1991) Why are stabilizations delayed? American Economic Review 81(5), 1170-1188.

Aschauer, D. A. (1985) Fiscal policy and aggregate demand. American Economic Review 75, 117-127.

Bai, Y., T. Kirsanova and C. B. Leith (2017) Nominal targeting in an economy with government debt. European Economic Review, Elsevier, 94(C), 103-125.

Benigno, P. and M. Woodford (2004) Optimal monetary and fiscal policy: A linear quadratic approach. In: M. Gertler and K. Rogoff (eds.), NBER Macroeconomics Annual, vol 18, pp 271-364.

Bilbiie, F. O., F. Ghironi and M. J. Melitz (2008) Monopoly Power and Endogenous Product Variety: Distortions and Remedies. NBER Working paper No. 14383.

Binmore, K. (1987) Nash bargaining theory II. In: K. Binmore and P. Dasgupta (eds.), The Economics of Bargaining, pp. 61-76. Oxford: Basil Blackwell Ltd. 
Bowen, T. R., Y. Chen and H. Eraslan (2014) Mandatory versus discretionary spending: The status quo effect. American Economic Review 104(10), 2941-2974.

Cai, H. (2000) Delay in multilateral bargaining under complete information. Journal of Economic Theory 93, 260-276.

Calvo, G. (1983) Staggered prices in a utility maximising framework. Journal of Monetary Economics 12(3), 383-398.

Chen, X., E. M. Leeper and C. Leith (2017) U.S. Monetary and Fiscal Policies Conflict or Cooperation. Working Paper.

Currie, D. and P. Levine (1993) Rules, Reputation and Macroeconomic Policy Coordination. Cambridge: Cambridge University Press.

D'Auria, F. (2015) The effects of fiscal shocks in a new Keynesian model with useful government spending. Macroeconomic Dynamics 19, 1380-1399.

Diaz-Giminez, J., G. Giovannetti, R. Marimon and P. Teles (2008) Nominal debt as a burden on monetary policy. Review of Economic Dynamics 11, 493-514.

Drazen, A. and V. Grilli (1993) The benefit of crises for economic reforms. American Economic Review 83(3), 598-607.

Ellison, M. and N. Rankin (2007) Optimal monetary policy when lump-sum taxes are unavailable: A reconsideration of the outcomes under commitment and discretion. Journal of Economic Dynamics and Control 31(1), 219-243.

Flamini, F. (2012) Recursive bargaining with dynamic accumulation. In: R. Johansoon and A. Rantzer (eds.), Distributed Decision Making and Control, Lecture Notes in Control and Information Sciences, vol. 417, pp. 131-144. London: Springer.

Gali, J. (1994) Government size and macroeconomic stability. European Economic Review 28, 117-132.

Heer, B. and A. Maussner (2009) Dynamic General Equilibrium Modelling, 2nd ed. London: Springer.

Hsieh, C. T. (2000) Bargaining over reform. European Economic Review 44(9), 1659-1676.

Karras, G. (1994) Government spending and private consumption: Some international evidence. Journal of Money, Credit and Banking 26(1), 9-22.

Katayama, K. (2008) Delay Fiscal Reform. Policy Research Institute Discussion Paper Series No. 08A-06, Ministry of Finance, Japan.

Klein, P., P. Krusell and J. V. Rios Rull (2008) Time consistent public policy. Review of Economic Studies 75, 1217-1246.

Leeper, E. M. (1991) Equilibria under 'active' and 'passive' monetary and fiscal policies. Journal of Monetary Economics 27, 129-147.

Leeper, E. M. and C. Leith, (2016) Understanding inflation as a joint monetary and fiscal phenomenon. In: Handbook of Macroeconomics, Chapter 30, vol. 2, pp. 2305-2415. Elsevier.

Leeper, E. M., C. Leith and D. Liu (2016) Optimal Time-Consistent Monetary, Fiscal and Debt Maturity Policy. Working Papers 2016_04, Business School - Economics, University of Glasgow.

Leeper, E. M., N. Traum and T. B. Walker (2017) Clearing up the fiscal multiplier morass. American Economic Review 107(8), 2409-2454.

Leith, C. and J. Malley (2005) Estimated general equilibrium models for the analysis of monetary policy in the US and Europe. European Economic Review 49(8), 2137-2159.

Leith, C. and S. Wren-Lewis (2013) Fiscal sustainability in a New Keynesian model. Journal of Money, Credit and Banking, Blackwell Publishing, 45(8), 1477-1516.

Levine, P, P. McAdam and J. Pearlman (2008) Quantifying and sustaining welfare gains from monetary commitment. Journal of Monetary Economics 55(7), 1253-1276.

Levine, P and J. Pearlman (2011) Computation of LQ Approximations to Optimal Policy Problems in Different Information Settings under Zero Lower Bound Constraint. Dynare Working Paper No. 10.

Lucas, R. E. and N. Stokey (1983) Optimal fiscal and monetary policy in an economy without capital. Journal of Monetary Economics 12(1), 55-93.

Martin, F. (2009) A positive theory of government debt. Review of Economic Dynamics 12(4), 608-631.

Martinelli, C. and R. Escorza (2007) When are stabilizations delayed? Alesina-Drazen revisited. European Economic Review 51(5), 1223-1245. 
Muthoo, A. (1995) Bargaining in a long run relationship with endogenous termination. Journal of Economic Theory 66(2), 590-598.

Muthoo, A. (1999) Bargaining Theory with Applications. Cambridge: Cambridge University Press.

Nicolini, J. P. (1998) More on the time consistency of monetary policy. Journal of Monetary Economics 41(2), 333-350.

Niemann, S. and P. Pilcher (2011) Optimal fiscal and monetary policy under rare disasters: The role of government debt and monetary conservatism. European Economic Review 55(1), 75-92.

Niemann, S., P. Pilcher and G. Sorger (2013a) Central bank independence and the monetary instrument problem. International Economic Review 54, 1031-1055.

Niemann, S., P. Pichler and G. Sorger (2013b) Public debt, discretionary policy, and inflation persistence. Journal of Economic Dynamics and Control 37(6), 1097-1109.

Obstfeld, M. (1991) A model of currency depreciation and the debt-inflation sprial. Journal of Economic Dynamics and Control 15(1), 151-177.

Obstfeld, M. (1997) Dynamic seigniorage theory: An exploration. Macroeconomic Dynamics 1, 588-614.

Orphanides, A. (1996) The timing of stabilizations. Journal of Economic Dynamics and Control 20(1-3), 257-279.

Osborne, G. (2010) Mais Lecture - A New Economic Model, February 24, 2010.

Rogoff, K. (1985) The Optimal Degree of Commitment to an Intermediate Monetary Target. Quarterly Journal of Economics 100, 1169-1189.

Rotemberg, J and M. Woodford (1997) An optimisation-based econometric framework for the evaluation of monetary policy. In: B. S. Bernanke and J. Rotemberg (ed.), NBER Macroeconomic Annual, pp. 297-346. Cambridge, MA: MIT Press.

Rubinstein, A. (1982) Perfect equilibrium in a bargaining game. Econometrica 50(1), 97-109.

Schmitt-Grohe, S. and M. Uribe (2004) Optimal monetary and fiscal policy under sticky prices. Journal of Economic Theory 114(2), 198-230.

Sibert, A. and W. Perraudin (2000) Timing of multilateral lending. Economic Journal 110, 192-211.

Sorger, G. (2006) Recursive Nash bargaining over a productive asset. Journal of Economic Dynamic and Control 30, 2637-2659.

Spolaore, E. (2004) Adjustments in different government systems. Economics and Politics 16(2), $117-146$.

Velasco, A. (2000) Debts and deficits with fragmented fiscal policymaking. Journal of Public Economics 76(1), 105-125.

Woodford, M. (2003) Interest and Prices: Foundations of a Theory of Monetary Policy. Princeton: Princeton University Press.

\section{APPENDIX A: DERIVING SOCIAL WELFARE}

\section{A.1. Flexible Price Equilibrium}

Profit-maximizing behavior implies that firms will operate at the point at which marginal costs equal marginal revenues

$$
\begin{aligned}
-\ln \left(\mu_{t}\right) & =m c_{t} \\
\left(1-\frac{1}{\epsilon}\right) & =\frac{(1-\varkappa)}{\left(1-\tau_{t}\right)}\left(N_{t}^{n}\right)^{\varphi} A_{t}^{-1}\left(C_{t}^{n}\right)^{\sigma} \xi_{t}^{N},
\end{aligned}
$$

where the $n$ superscript denotes the flexible price equilibrium. In the steady state, this reduces to

$$
\left(1-\frac{1}{\bar{\epsilon}}\right)=\frac{(1-\varkappa)}{(1-\bar{\tau})}\left(\bar{N}^{n}\right)^{\varphi}\left(\bar{C}^{n}\right)^{\sigma}
$$


If the subsidy $\varkappa$ is given by

$$
(1-\varkappa)=\left(1-\frac{1}{\bar{\epsilon}}\right)(1-\bar{\tau})
$$

then

$$
\left(\bar{C}^{n}\right)^{-\sigma}=\left(\bar{N}^{n}\right)^{\varphi},
$$

which is identical to the optimal level of employment in the efficient steady state. Given the steady-state government spending rule

$$
\frac{\bar{G}}{\bar{Y}}=\left(1+\chi^{-\frac{1}{\sigma}}\right)^{-1},
$$

the steady-state level of output is given by

$$
\bar{Y}=\bar{N}=\left(1+\chi^{\frac{1}{\sigma}}\right)^{\frac{\sigma}{\sigma+\varphi}},
$$

and, if the subsidy is in place, then the steady-state real wage is given by

$$
\bar{w}=\frac{1}{1-\bar{\tau}} .
$$

The steady-state tax rate required to support a given debt-GDP ratio is given by

$$
\bar{\tau}=\frac{(1-\beta) \frac{\bar{B}}{\bar{Y}}+\frac{\bar{G}}{\bar{Y}}}{1+(1-\beta) \frac{\bar{B}}{\bar{Y}}+\frac{\bar{G}}{\bar{Y}}},
$$

and the tax revenues relative to debt are given by

$$
\frac{\bar{w} \bar{N} \bar{\tau}}{\bar{b}}=\frac{\frac{\bar{\tau}}{1-\bar{\tau}}}{\frac{\bar{B}}{\overline{\bar{Y}}}} .
$$

This is sufficient to define all log-linearized relationships dependent on model parameters and the debt-GDP ratio.

\section{A.2. Derivation of Social Welfare}

Individual utility in period $t$ is

$$
\frac{C_{t}^{1-\sigma} \xi_{t}^{-\sigma}}{1-\sigma}+\chi \frac{G_{t}^{1-\sigma} \xi_{t}^{-\sigma}}{1-\sigma}-\frac{N_{t}^{1+\varphi} \xi_{t}^{-\sigma} \xi_{t}^{N}}{1+\varphi}
$$

Before considering the elements of the utility function, we need to note the following general result relating to second-order approximations

$$
\frac{Y_{t}-Y}{Y_{t}}=\widehat{Y}_{t}+\frac{1}{2} \widehat{Y}_{t}^{2}+O[2]
$$

where $\widehat{Y}_{t}=\ln \left(\frac{Y_{t}}{Y}\right), O[2]$ represents terms that are of order higher than 2 in the bound on the amplitude of the relevant shocks. This will be used in various places in the derivation of welfare. Now consider the second-order approximation to the first term, 


$$
\begin{aligned}
\frac{C_{t}^{1-\sigma} \xi_{t}^{-\sigma}}{1-\sigma}= & \bar{C}^{1-\sigma}\left(\frac{C_{t}-\bar{C}}{\bar{C}}\right)-\frac{\sigma}{2} \bar{C}^{1-\sigma}\left(\frac{C_{t}-\bar{C}}{\bar{C}}\right)^{2} \\
& -\sigma \bar{C}^{1-\sigma}\left(\frac{C_{t}-\bar{C}}{\bar{C}}\right)\left(\xi_{t}-1\right)+t i p+O[2],
\end{aligned}
$$

where tip represents "terms independent of policy". Using the results above, this can be rewritten in terms of hatted variables

$$
\frac{C_{t}^{1-\sigma} \xi_{t}^{-\sigma}}{1-\sigma}=\bar{C}^{1-\sigma}\left(\widehat{C}_{t}+\frac{1}{2}(1-\sigma) \widehat{C}_{t}^{2}-\sigma \widehat{C}_{t} \widehat{\xi}_{t}\right)+t i p+O[2] .
$$

Similarly for the term in government spending

$$
\chi \frac{G_{t}^{1-\sigma} \xi_{t}^{-\sigma}}{1-\sigma}=\chi \bar{G}^{1-\sigma}\left(\widehat{G}_{t}+\frac{1}{2}(1-\sigma) \widehat{G}_{t}^{2}-\sigma \widehat{G}_{t} \widehat{\xi}_{t}\right)+t i p+O[2] .
$$

The final term in labor supply can be written as

$$
\frac{N_{t}^{1+\varphi} \xi_{t}^{N} \xi_{t}^{-\sigma}}{1+\varphi}=\bar{N}^{1+\varphi}\left(\widehat{N}_{t}+\frac{1}{2}(1+\varphi) \widehat{N}_{t}^{2}-\sigma \widehat{N}_{t} \widehat{\xi}_{t}+\widehat{N}_{t} \widehat{\xi}_{t}^{N}\right)+t i p+O[2] .
$$

Now, we need to relate the labor input to output and a measure of price dispersion. Aggregating the individual firms' demand for labor yields

$$
N_{t}=\left(\frac{Y_{t}}{A_{t}}\right) \int_{0}^{1}\left(\frac{P_{t}(i)}{P_{t}}\right)^{-\epsilon} d i .
$$

It can be shown (see Woodford (2003), Chapter 6) that

$$
\begin{aligned}
\widehat{N}_{t} & =\widehat{Y}_{t}-a_{t}+\ln \left[\int_{0}^{1}\left(\frac{P_{t}(i)}{P_{t}}\right)^{-\epsilon} d i\right] \\
& =\widehat{Y}_{t}-a_{t}+\frac{\epsilon}{2} \operatorname{var}_{i}\left(p_{t}(i)\right)+O[2],
\end{aligned}
$$

so we can write

$$
\begin{aligned}
\frac{N_{t}^{1+\varphi} \xi_{t}^{N} \xi_{t}^{-\sigma}}{1+\varphi}= & \bar{N}^{1+\varphi}\left[\widehat{Y}_{t}+\frac{1}{2}(1+\varphi) \widehat{Y}_{t}^{2}-(1+\varphi) \widehat{Y}_{t} a_{t}+\widehat{Y}_{t} \widehat{\xi}_{t}^{N}-\sigma \widehat{Y}_{t} \widehat{\xi}_{t}+\frac{\epsilon}{2} \operatorname{var}_{i}\left(p_{t}(i)\right)\right] \\
& +t i p+O[2] .
\end{aligned}
$$

Using these expansions, individual utility can be written as

$$
\begin{aligned}
\Gamma_{t}= & \bar{C}^{1-\sigma}\left[\widehat{C}_{t}+\frac{1}{2}(1-\sigma) \widehat{C}_{t}^{2}-\sigma \widehat{C}_{t} \widehat{\xi}_{t}\right] \\
& +\chi \bar{G}^{1-\sigma}\left[\widehat{G}_{t}+\frac{1}{2}(1-\sigma) \widehat{G}_{t}^{2}-\sigma \widehat{G}_{t} \widehat{\xi}_{t}\right] \\
& -\bar{N}^{1+\varphi}\left[\widehat{Y}_{t}+\frac{1}{2}(1+\varphi) \widehat{Y}_{t}^{2}-(1+\varphi) \widehat{Y}_{t} a_{t}\right. \\
& \left.-\sigma \widehat{Y}_{t} \widehat{\xi}_{t}+\widehat{Y}_{t} \widehat{\xi}_{t}^{N}+\frac{\epsilon}{2} \operatorname{var}_{i}\left(p_{t}(i)\right)\right] \\
& +t i p+O[2] .
\end{aligned}
$$


Using second-order approximation to the national accounting identity

$$
\theta \widehat{C}_{t}=\widehat{Y}_{t}-(1-\theta) \widehat{G}_{t}-\frac{1}{2} \theta \widehat{C}_{t}^{2}-\frac{1}{2}(1-\theta) \widehat{G}_{t}^{2}+\frac{1}{2} \widehat{Y}_{t}^{2}+O[2] .
$$

With the steady-state subsidy in place and government spending chosen optimally, the following conditions hold in the steady state, $\bar{C}^{1-\sigma}$

$$
\bar{C}^{1-\sigma}=\bar{N}^{1+\varphi} \theta,
$$

and

$$
\chi \bar{G}^{1-\sigma}=\bar{N}^{1+\varphi}(1-\theta)
$$

which allows us to eliminate the levels terms and rewrite welfare as

$$
\begin{aligned}
\Gamma_{t}= & \bar{C}^{1-\sigma}\left[-\frac{1}{2} \sigma \widehat{C}_{t}^{2}-\sigma \widehat{C}_{t} \widehat{\xi}_{t}\right]+\chi \bar{G}^{1-\sigma}\left[-\frac{1}{2} \sigma \widehat{G}_{t}^{2}-\sigma \widehat{G}_{t} \widehat{\xi}_{t}\right] \\
& -\bar{N}^{1+\varphi}\left[\frac{1}{2} \varphi \widehat{Y}_{t}^{2}-(1+\varphi) \widehat{Y}_{t} a_{t}-\sigma \widehat{Y}_{t} \widehat{\xi}_{t}+\widehat{Y}_{t} \widehat{\xi}_{t}^{N}+\frac{\epsilon}{2} \operatorname{var}_{i}\left(p_{t}(i)\right)\right] \\
& +\operatorname{tip}+O[2] .
\end{aligned}
$$

We now need to rewrite this in gap form using the FOCs for the social planner to eliminate the term in the technology shock

$$
\begin{aligned}
\Gamma_{t}= & -\bar{N}^{1+\varphi} \frac{1}{2}\left[\sigma \theta\left(\widehat{C}_{t}-\widehat{C}_{t}^{*}\right)^{2}+\sigma(1-\theta)\left(\widehat{G}_{t}-\widehat{G}_{t}^{*}\right)^{2}+\varphi\left(\widehat{Y}_{t}-\widehat{Y}_{t}^{*}\right)^{2}+\epsilon \operatorname{var}_{i}\left(p_{t}(i)\right)\right] \\
& +t i p+O[2] .
\end{aligned}
$$

Using the result from Woodford (2003) that

$$
\sum_{t=0}^{\infty} \beta^{t} \operatorname{var}_{i}\left(p_{t}(i)\right)=\frac{\theta}{(1-\theta)(1-\theta \beta)} \sum_{t=0}^{\infty} \beta^{t} \pi_{t}^{2}+t i p+O[2],
$$

we can write the discounted sum of utility as

$$
\begin{aligned}
\Gamma= & -\bar{N}^{1+\varphi} \frac{1}{2} E_{0} \sum_{t=0}^{\infty} \beta^{t}\left[\sigma \theta\left(\widehat{C}_{t}-\widehat{C}_{t}^{*}\right)^{2}+\sigma(1-\theta)\left(\widehat{G}_{t}-\widehat{G}_{t}^{*}\right)^{2}+\varphi\left(\widehat{Y}_{t}-\widehat{Y}_{t}^{*}\right)^{2}+\frac{\epsilon}{\gamma} \pi_{t}^{2}\right] \\
& + \text { tip }+O[2] .
\end{aligned}
$$

\section{A.3. The budget constraint using gap variables}

The log-linearized budget constraint is given by

$$
\begin{aligned}
\widehat{b}_{t-1}-\pi_{t}= & \beta \widehat{b}_{t}-\beta E_{t}\left[\pi_{t+1}+\sigma\left(\widehat{C}_{t+1}+\widehat{\xi}_{t+1}\right)\right] \\
& +\frac{\bar{w} \bar{N} \bar{\tau}}{\bar{b}}\left(\widehat{w}_{t}+\widehat{N}_{t}+\widehat{\tau}_{t}\right)-\frac{\bar{G}}{\bar{b}} \widehat{G}_{t}+\sigma \beta\left(\widehat{C}_{t}+\widehat{\xi}_{t}\right) .
\end{aligned}
$$


Using the labor supply function to eliminate real wages and the definition of efficient output to eliminate the technology shock

$$
\begin{aligned}
\widehat{b}_{t-1}-\pi_{t}= & \beta \widehat{b}_{t}-\beta E_{t}\left[\pi_{t+1}+\sigma\left(\widehat{C}_{t+1}+\widehat{\xi}_{t+1}\right)\right] \\
& +\sigma \beta\left(\widehat{C}_{t}+\widehat{\xi}_{t}\right)-\frac{\bar{G}}{\bar{b}} \widehat{G}_{t} \\
& +\frac{\bar{w} \bar{N} \bar{\tau}}{\bar{b}}\left[(1+\varphi)\left(\widehat{Y}_{t}-\widehat{Y}_{t}^{*}\right)+\frac{1}{1-\bar{\tau}} \widehat{\tau}_{t}+\sigma\left(\widehat{C}_{t}-\widehat{C}_{t}^{*}\right)+\widehat{Y}_{t}^{*}\right] .
\end{aligned}
$$

Gapping the remaining variables and combining shock terms

$$
\begin{aligned}
\widehat{b}_{t-1}-\pi_{t}= & \beta \widehat{b}_{t}-\beta E_{t}\left[\pi_{t+1}+\sigma\left(\widehat{C}_{t+1}-\widehat{C}_{t+1}^{*}\right)\right]-f_{t} \\
& +\sigma \beta\left(\widehat{C}_{t}-\widehat{C}_{t}^{*}\right)-\frac{\bar{G}}{\bar{b}}\left(\widehat{G}_{t}-\widehat{G}_{t}^{*}\right) \\
& +\frac{\bar{w} \bar{N} \bar{\tau}}{\bar{b}}\left[(1+\varphi)\left(\widehat{Y}_{t}-\widehat{Y}_{t}^{*}\right)+\frac{1}{1-\bar{\tau}}\left(\widehat{\tau}_{t}-\widehat{\tau}_{t}^{*}\right)+\sigma\left(\widehat{C}_{t}-\widehat{C}_{t}^{*}\right)\right],
\end{aligned}
$$

where

$$
f_{t}=-(\sigma+(1-\sigma)(1-\beta))\left(\frac{(1+\varphi)}{\sigma+\varphi} a_{t}-\frac{\widehat{\xi}_{t}^{N}}{\sigma+\varphi}\right)-\frac{\bar{w} \bar{N}}{\bar{b}} \mu_{t}-\sigma \beta \widehat{\xi}_{t},
$$

captures the fiscal consequences of the various shocks hitting the economy.

\section{APPENDIX B: PROOF OF PROPOSITION 1}

Party $i$ will solve the following Lagrangian:

$$
\begin{aligned}
L^{i}\left(\mathbf{S}_{t-1}\right)= & V^{i}\left(\mathbf{S}_{t-1}\right)+\lambda_{i}\left(W^{j}\left(\mathbf{S}_{t-1}\right)-X(1-\delta)-\delta V^{j}\left(\mathbf{S}_{t-1}\right)\right) \\
& +m_{1 i}\left(\mathbf{S}_{t}-\mathbf{D} 1^{i} \mathbf{S}_{t-1}-\mathbf{D} 2^{i} \mathbf{u}_{i t}\right)+m_{2 i}\left(\pi_{t}-\mathbf{C 1}^{i} \mathbf{S}_{t-1}-\mathbf{C} 2^{i} \mathbf{u}_{i t}\right),
\end{aligned}
$$

where $\lambda_{i} \geq 0$ is the Kuhn-Tucker multiplier (equal to zero when the constraint is slack), $m_{1 i}, m_{2 i} \in \mathbb{R}$ are the Lagrangian multipliers, $V^{i}\left(\mathbf{S}_{t-1}\right)$ and $W^{j}\left(\mathbf{S}_{t-1}\right)$ are as in (31) and (32), with $i, j=1,2$ and $i \neq j$.

The FOCs of this Lagrangian with respect to $\mathbf{u}_{i t}, \pi_{t}, \mathbf{S}_{t}$ and the multipliers are as follows

$$
\begin{aligned}
b\left[\mathbf{Q}^{i \prime}+\mathbf{Q}^{i}+\lambda_{i}\left(\mathbf{Q}^{j \prime}+\mathbf{Q}^{j}\right)\right] \mathbf{u}_{i t}+\mathbf{D} 2^{i \prime} m_{1 i}+\mathbf{C} 2^{i \prime} m_{2 i} & =0 \\
-2 b\left(\mathbf{R}^{i}+\lambda_{i} \mathbf{R}^{j}\right) \pi_{t}+m_{2 i} & =0 \\
\beta \frac{\partial E_{t} C^{i}\left(\mathbf{S}_{t}\right)}{\partial \mathbf{S}_{t}}+\lambda_{i} \beta \frac{\partial E_{t} C^{j}\left(\mathbf{S}_{t}\right)}{\partial \mathbf{S}_{t}}+m_{1 i} & =0 \\
\lambda_{i}\left[W^{j}\left(\mathbf{S}_{t-1}\right)-X(1-\delta)-\delta V^{j}\left(\mathbf{S}_{t-1}\right)\right] & =0 \\
\mathbf{S}_{t}-\mathbf{D} 1^{i} \mathbf{S}_{t-1}-\mathbf{D} 2^{i} \mathbf{u}_{i t} & =0 \\
\pi_{t}-\mathbf{C 1}^{i} \mathbf{S}_{t-1}-\mathbf{C 2}^{i} \mathbf{u}_{i t} & =0
\end{aligned}
$$

(i.e., $\lambda_{i}=0$ for $\left.W^{j}\left(\mathbf{S}_{t-1}\right)>X(1-\delta)+\delta V^{j}\left(\mathbf{S}_{t-1}\right)\right)$.

Given $E_{t} C^{i}\left(\mathbf{S}_{t}\right)=A-b \mathbf{S}_{t} \boldsymbol{\beta}^{i} \mathbf{S}_{t}$ in (38), condition (B3) can also be written as follows,

$$
m_{1 i}=-b \beta\left[\left(\boldsymbol{\beta}^{i}+\boldsymbol{\beta}^{i \prime}\right)+\lambda_{i}\left(\boldsymbol{\beta}^{j}+\boldsymbol{\beta}^{j \prime}\right)\right] \mathbf{S}_{t} .
$$


This, together with (B2), implies that (B1) becomes

$$
\begin{gathered}
\left\{\mathbf{Q}^{i \prime}+\mathbf{Q}^{i}+\lambda_{i}\left(\mathbf{Q}^{j \prime}+\mathbf{Q}^{j}\right)+\beta \mathbf{D} 2^{i \prime}\left[\boldsymbol{\beta}^{i}+\boldsymbol{\beta}^{i \prime}+\lambda_{i}\left(\boldsymbol{\beta}^{j}+\beta^{j \prime}\right)\right] \mathbf{D} 2^{i}\right\} \mathbf{u}_{i t} \\
+2 \mathbf{C} 2^{i \prime}\left(\mathbf{R}^{i}+\lambda_{i} \mathbf{R}^{j}\right) \mathbf{C} 2^{i} \mathbf{u}_{i t}+ \\
+\left\{\beta \mathbf{D} 2^{i \prime}\left[\boldsymbol{\beta}^{i}+\beta^{i \prime}+\lambda_{i}\left(\boldsymbol{\beta}^{j}+\boldsymbol{\beta}^{j \prime}\right)\right] \mathbf{D} 1^{i}+2 \mathbf{C} 2^{i \prime}\left(\mathbf{R}^{i}+\lambda_{i} \mathbf{R}^{j}\right) \mathbf{C} \mathbf{1}^{i}\right\} \mathbf{S}_{t-1}=0,
\end{gathered}
$$

or

$$
\left(\mathbf{E} 1^{i}+\lambda_{i} \mathbf{R} \mathbf{1}^{j}\right) \mathbf{S}_{t-1}+\left(\mathbf{E} \mathbf{0}^{i}+\lambda_{i} \mathbf{R} \mathbf{0}^{j}\right) \mathbf{u}_{i t}=0
$$

where

$$
\begin{aligned}
& \underset{3 x 1^{i}}{\mathbf{E}}=2 \mathbf{C} 2^{i \prime} \mathbf{R}^{i} \mathbf{C} 1^{i}+\beta \mathbf{D} 2^{i \prime}\left(\boldsymbol{\beta}^{i}+\beta^{i \prime}\right) \mathbf{D} 1^{i} \\
& \underset{3 x 3}{\mathbf{E} 0^{i}}=2 \mathbf{C} 2^{i \prime} \mathbf{R}^{i} \mathbf{C} 2^{i}+\mathbf{Q}^{i}+\mathbf{Q}^{i \prime}+\beta \mathbf{D 2}^{i \prime}\left(\boldsymbol{\beta}^{i}+\boldsymbol{\beta}^{i \prime}\right) \mathbf{D} 2^{i} \\
& \underset{3 x 1}{\mathbf{R} 1^{j}}=2 \mathbf{R}^{j} \mathbf{C} 2^{i \prime} \mathbf{C} 1^{i}+\beta \mathbf{D} 2^{i \prime}\left(\boldsymbol{\beta}^{j}+\beta^{j \prime}\right) \mathbf{D} 1^{i} \\
& \underset{3 x 0^{j}}{\mathbf{R}}=2 \mathbf{R}^{j} \mathbf{C} 2^{i \prime} \mathbf{C} 2^{i}+\mathbf{Q}^{j}+\mathbf{Q}^{j \prime}+\beta \mathbf{D} 2^{i \prime}\left(\boldsymbol{\beta}^{j}+\boldsymbol{\beta}^{j \prime}\right) \mathbf{D} 2^{i} .
\end{aligned}
$$

Hence,

$$
\mathbf{u}_{i t}=-\left(\mathbf{L} \mathbf{0}^{i}\right)^{-1} \mathbf{L} \mathbf{1}^{i} \mathbf{S}_{t-1},
$$

where $\mathbf{L} \mathbf{J}^{i}=\mathbf{E} \mathbf{J}^{i}+\lambda_{i} \mathbf{R} \mathbf{J}^{j}$ with $\mathbf{J}=\mathbf{0}, \mathbf{1}, i, j=1,2$ and $i \neq j$. This allows us to obtain $\mathbf{u}_{i t}=$ $\mathbf{O 1}^{i} \mathbf{S}_{t-1}$, as in (39) where

$$
\mathbf{O} \mathbf{1}^{i} \equiv-\left(\mathbf{L O}^{i}\right)^{-1} \mathbf{L} \mathbf{1}^{i} .
$$

Using the optimal controls (B10) in (B6), the inflation rate can be written as a linear function of the state

$$
\pi_{t}=\mathbf{P} \mathbf{0}^{i} \mathbf{S}_{t-1}
$$

where

$$
\mathbf{P 0}{ }^{i}=\mathbf{C 1} 1^{i}+\mathbf{C 2}^{i} \mathbf{O} 1^{i} .
$$

Similarly, the equation of motion $\mathbf{S}_{t}=\mathbf{D} 1^{i} \mathbf{S}_{t-1}+\mathbf{D} 2^{i} \mathbf{u}_{i t}$ becomes

$$
\mathbf{S}_{t}=\mathbf{G 1}^{i} \mathbf{S}_{t-1}
$$

with

$$
\mathbf{G} 1^{i}=\mathbf{D} 1^{i}+\mathbf{D} 2^{i} \mathbf{O} 1^{i} .
$$

We can now derive the guessed coefficients in the forecasts (19). Leading (B12) one period and taking expectations, we can obtain

$$
E_{t}\left(\pi_{t+1}\right)=\left(q^{i} \mathbf{P} \mathbf{0}^{i}+\left(1-q^{i}\right) \mathbf{P} \mathbf{0}^{j}\right) \mathbf{S}_{t} .
$$

Then, it must be

$$
f^{i}=q^{i} \mathbf{P} \mathbf{0}^{i}+\left(1-q^{i}\right) \mathbf{P} \mathbf{0}^{j},
$$

for $i=1,2$. This implies that $f^{1}=f^{2}$, since $q^{1}=1-q^{2}$.

Similarly, using equation (39) led one period, we obtain

$$
c_{i t+1}^{g}=\mathbf{O 1}{ }_{11}^{i} \mathbf{S}_{t},
$$


where $\mathbf{O} \mathbf{1}_{11}^{i}$ indicates the first term of the vector $\mathbf{O} \mathbf{1}^{i}$ and therefore,

$$
E_{t}\left(c_{t+1}^{g}\right)=\left(q^{i} \mathbf{O} 1_{11}^{i}+\left(1-q^{i}\right) \mathbf{O} 1_{11}^{j}\right) \mathbf{S}_{t} .
$$

It must be that

$$
c^{i}=q^{i} \mathbf{O} 1_{11}^{i}+\left(1-q^{i}\right) \mathbf{O 1} 1_{11}^{j},
$$

and again $c^{1}=c^{2}$, for $q^{1}=1-q^{2}$.

The expected value of the game continuation can now be written as a function of the state variable only

$$
E_{t} C^{i}\left(\mathbf{S}_{t}\right)=A-b\left(\mathbf{G} 1^{i} \mathbf{S}_{t-1}\right)^{\prime} \boldsymbol{\beta}^{i} \mathbf{G} \mathbf{1}^{i} \mathbf{S}_{t-1} .
$$

Using, the latter, $\mathbf{u}_{i t}=\mathbf{O 1}^{i} \mathbf{S}_{t-1}$, (B12) and (B14) in the Bellman equation (31), the value function $V^{i}\left(\mathbf{S}_{t-1}\right)$ can be written as follows

$$
V^{i}\left(\mathbf{S}_{t-1}\right)=A-b\left[\mathbf{S}_{t-1}\left(\mathbf{P 0}^{i^{\prime}} \mathbf{R}^{i} \mathbf{P} \mathbf{0}^{i}+\mathbf{O 1}^{i^{\prime}} Q^{i} \mathbf{O} 1^{i}+\beta \mathbf{G} \mathbf{1}^{i \prime} \boldsymbol{\beta}^{i} \mathbf{G} \mathbf{1}^{i}\right) \mathbf{S}_{t-1}\right] .
$$

Given the guessed parameters for the value function (see (36)), then the following equation must hold

$$
\boldsymbol{\Phi}^{i}=\mathbf{P} \mathbf{0}^{i^{\prime}} \mathbf{R}^{i} \mathbf{P} \mathbf{0}^{i}+\mathbf{O} 1^{i^{\prime}} Q^{i} \mathbf{O} 1^{i}+\beta \mathbf{G} \mathbf{1}^{i^{\prime}} \boldsymbol{\beta}^{i} \mathbf{G} \mathbf{1}^{i} .
$$

Following the same procedure for the expected discounted payoff of a responder, we can obtain an additional equation for the guessed coefficients $\boldsymbol{\mu}^{i}$ with $i=1,2$. First, we input the optimal control $\mathbf{u}_{i t}=\mathbf{O} 1^{i} \mathbf{S}_{t-1}$ in $W^{j}\left(\mathbf{S}_{t-1}\right)$ to obtain

$$
\begin{aligned}
W^{j}\left(\mathbf{S}_{t-1}\right)= & A-b\left[\left(\mathbf{P 0}^{i} \mathbf{S}_{t-1}\right)^{\prime} \mathbf{R}^{j}\left(\mathbf{P 0}^{i} \mathbf{S}_{t-1}\right)+\left(\mathbf{O} 1^{i} \mathbf{S}_{t-1}\right)^{\prime} Q^{j}\left(\mathbf{O 1}^{i} \mathbf{S}_{t-1}\right)\right. \\
& \left.+\beta\left(\mathbf{G 1}^{i} \mathbf{S}_{t-1}\right)^{\prime} \boldsymbol{\beta}^{j}\left(\mathbf{G 1}^{i} \mathbf{S}_{t-1}\right)\right] .
\end{aligned}
$$

Then, given the guessed parameters in (37), we can impose the next sets of equations

$$
\boldsymbol{\mu}^{j}=\mathbf{P} \mathbf{0}^{i^{\prime}} \mathbf{R}^{j} \mathbf{P} \mathbf{0}^{i}+\mathbf{O 1}^{i^{\prime}} Q^{j} \mathbf{O} \mathbf{1}^{i}+\beta \mathbf{G} \mathbf{1}^{i^{\prime}} \boldsymbol{\beta}^{j} \mathbf{G} \mathbf{1}^{i},
$$

with $i, j=1,2$ and $i \neq j$.

The sets of equations in $\boldsymbol{\Phi}^{i}$ and $\boldsymbol{\mu}^{i}$ together with

$$
\boldsymbol{\beta}^{i}=q^{i} \boldsymbol{\Phi}^{i}+\left(1-q^{i}\right) \boldsymbol{\mu}^{i}
$$

allow us to obtain $3 \times 2$ equations in the $3 \times 2$ guessed coefficients $\left(\boldsymbol{\beta}^{i}, \boldsymbol{\Phi}^{i}\right.$ and $\boldsymbol{\mu}^{i}$, with $i=1,2)$. Finally, to fully determine the guesses, we need to solve for the multiplier $\lambda_{i}$. Condition (B4) can be written as

$$
\lambda_{i}\left((1-\delta)(X-A)+b \mathbf{S}_{t-1}\left(\boldsymbol{\mu}^{j}-\delta \boldsymbol{\Phi}^{j}\right) \mathbf{S}_{t-1}\right)=0 .
$$

Generally, for interior solutions $\left(\lambda_{i}>0\right)$, the policies will not be time-invariant (since the multiplier depends on the state, $\mathbf{S}_{t-1}$ ). Also players would potentially be able to make offers without any concessions $\left(\lambda_{i}=0\right)$ when disagreement disutility is sufficiently high, such that

$$
(1-\delta)(X-A)+b \mathbf{S}_{t-1}\left(\boldsymbol{\mu}^{j}-\delta \boldsymbol{\Phi}^{j}\right) \mathbf{S}_{t-1}<0 .
$$

However, in the most interesting case in which $\delta$ goes to 1 , we have interior solutions $\left(\lambda_{i}>0\right)$ for $\boldsymbol{\mu}^{j}=\delta \boldsymbol{\Phi}^{j}$, for $i, j=1,2$ and $i \neq j$. Then, the multipliers are independent of the state and the controls $\mathbf{u}_{i t}$ are linear (time-invariant) function of the state. ${ }^{26}$ To conclude, 
the multipliers and the guesses are derived from (B18), (B19), and (B20), with the forecast coefficients as in (B16), (B17), and the indifference conditions being written as

$$
\boldsymbol{\mu}^{j}=\delta \boldsymbol{\Phi}^{j},
$$

with $\delta \rightarrow 1$, for $i, j=1,2$ and $i \neq j$.

\section{APPENDIX C: INTRODUCING AN INDEPENDENT CENTRAL BANK}

The first step is to write the problem in matrix form as before, but splitting the controls of the CB from those of the two fiscal players. The budget constraint, similarly to (20), becomes

$$
\mathbf{B} 0^{i} \mathbf{S}_{t}=\mathbf{S}_{t-1}+\left[\begin{array}{ll}
\mathbf{B} 2_{1,2} & \mathbf{B} 2_{1,3}
\end{array}\right] \mathbf{u}_{i t}+\left[\mathbf{B} 2_{1,1}\right] c_{t}^{g} .
$$

Then, if at period $t$, the CB implements its policy, as reflected in $c_{t}^{g}$, and players agree on party $i$ 's proposed policy $\mathbf{u}_{i t}$, the state $\mathbf{S}_{t}$ becomes

$$
\mathbf{S}_{t}=\mathbf{D} 1^{i} \mathbf{S}_{t-1}+\mathbf{D} 2^{i} \mathbf{u}_{i t}+\mathbf{D 3}^{i} c_{t}^{g}
$$

with

$$
\begin{gathered}
\mathbf{D} 1^{i}=\left[\mathbf{B} \mathbf{0}^{i}\right]^{-1} \\
\mathbf{D 2}^{i}=\left[\mathbf{B} \mathbf{0}^{i}\right]^{-1}\left[\mathbf{B} 2_{1,2} \quad \mathbf{B 2}_{1,3}\right] \\
\mathbf{D 3}^{i}=\left[\mathbf{B} 0^{i}\right]^{-1}\left[\mathbf{B 2}_{1,1}\right] .
\end{gathered}
$$

Then, using (24)

$$
E_{t} \pi_{t+1}=\mathbf{A} \mathbf{1} \pi_{t}+\mathbf{A} \mathbf{2} \mathbf{u}_{i t}+\mathbf{A} \mathbf{3} c_{t}^{g},
$$

with

$$
\begin{aligned}
& \mathbf{A 1}=\left[\frac{1}{\beta}\right] \text { and }, \\
& \mathbf{A 2}=\left[-\frac{\gamma\left((1-\beta) \frac{\bar{B}}{\bar{Y}}+(1-\theta)\right)}{\beta}-\frac{\gamma \varphi(1-\theta)}{\beta}\right] \\
& \mathbf{A} \mathbf{3}=\left[-\frac{\gamma(\varphi \theta+\sigma)}{\beta}\right] .
\end{aligned}
$$

This, together with the forecast $E_{t}\left(\pi_{t+1}\right)=f^{i} \mathbf{S}_{t}$, implies that inflation can be written as:

$$
\pi_{t}=\mathbf{C} 1^{i} \mathbf{S}_{t-1}+\mathbf{C} 2^{i} \mathbf{u}_{i t}+\mathbf{C} 3^{i} c_{t}^{g}
$$

where

$$
\mathbf{C 1}{ }^{i}=[\mathbf{A} \mathbf{1}]^{-1}\left[f^{i} \mathbf{D} 1^{i}\right]
$$




$$
\begin{aligned}
\mathbf{C 2} & =[\mathbf{A} 1]^{-1}\left[f^{i} \mathbf{D} 2^{i}-\mathbf{A} 2\right] \\
\mathbf{C} 3^{i} & =[\mathbf{A} 1]^{-1}\left[f^{i} \mathbf{D} 3^{i}-\mathbf{A} 3\right] .
\end{aligned}
$$

Therefore, the evolution of the state, government debt, and inflation follow a similar structure to (23) and (25) but where we distinguish the political parties' and the CB's controls.

The next step is to set and solve the problems for the political parties and the CB.

Fiscal Authorities' Problem. We begin by considering the bargaining game between the two fiscal players, conditional on the policy of the $\mathrm{CB}$. The per-period objective function for party $i$ in matrix form is as follows

$$
l\left(x_{i}^{c}, x_{i}^{g}, x_{i}^{y}, x_{i}^{\pi}\right)=\pi_{t} \mathbf{R}^{i} \pi_{t}+c_{t}^{g} \mathbf{Q}_{1}^{i} c_{t}^{g}+\mathbf{u}_{i t}^{\prime} \mathbf{Q}_{2}^{i} \mathbf{u}_{i t}+c_{t}^{g} \mathbf{Q}_{3}^{i} \mathbf{u}_{i t},
$$

where

$$
\begin{aligned}
& \mathbf{Q}_{1}^{i}=\theta\left(\sigma x_{i}^{c}+\varphi \theta x_{i}^{y}\right) \\
& \mathbf{Q}_{2}^{i}=\left[\begin{array}{ll}
0 & 0 \\
0 & (1-\theta)\left(\sigma x_{i}^{g}+\varphi x_{i}^{y}(1-\theta)\right)
\end{array}\right] \\
& \mathbf{Q}_{3}^{i}=\left[\begin{array}{ll}
0 & 2(1-\theta) \theta \varphi x_{i}^{y}
\end{array}\right] .
\end{aligned}
$$

Then, the payoff to player $i$ when making an acceptable policy $\mathbf{u}_{i t}$ is

$$
\begin{aligned}
V^{i \prime}\left(\mathbf{S}_{t-1}\right)= & A-\min _{\mathbf{u}_{i t}}\left(b\left(\pi_{t} \mathbf{R}^{i} \pi_{t}+c_{t}^{g} \mathbf{Q}_{1}^{i} c_{t}^{g}+\mathbf{u}_{i t}^{\prime} \mathbf{Q}_{2}^{i} \mathbf{u}_{i t}+c_{t}^{g} \mathbf{Q}_{3}^{i} \mathbf{u}_{i t}\right)\right. \\
& \left.+\beta E_{t} C^{i}\left(\mathbf{S}_{t}\right)\right) .
\end{aligned}
$$

Similarly, for player $j$ when accepts the policy $\mathbf{u}_{i t}$, his payoff is

$$
\begin{aligned}
W^{j}\left(\mathbf{S}_{t-1}\right)= & A-b\left(\pi_{t} \mathbf{R}^{j} \pi_{t}+c_{t}^{g} \mathbf{Q}_{1}^{j} c_{t}^{g}+\mathbf{u}_{i t}^{\prime} \mathbf{Q}_{2}^{j} \mathbf{u}_{i t}+c_{t}^{g} \mathbf{Q}_{3}^{j} \mathbf{u}_{i t}\right) \\
& +\beta E_{t} C^{j}\left(\mathbf{S}_{t}\right) .
\end{aligned}
$$

Hence, the Lagrangian for this problem is as follows

$$
\begin{aligned}
L^{i}\left(\mathbf{S}_{t-1}\right)= & V^{i}\left(\mathbf{S}_{t-1}\right)+\lambda_{i}\left(W^{j}\left(\mathbf{S}_{t-1}\right)-X(1-\delta)-\delta V^{j}\left(\mathbf{S}_{t-1}\right)\right) \\
& +m_{1 i}\left(\mathbf{S}_{t}-\mathbf{D} 1^{i} \mathbf{S}_{t-1}-\mathbf{D} 2^{i} \mathbf{u}_{i t}-\mathbf{D} 3^{i} c_{t}^{g}\right)+m_{2 i}\left(\pi_{t}-\mathbf{C} 1^{i} \mathbf{S}_{t-1}-\mathbf{C} 2^{i} \mathbf{u}_{i t}-\mathbf{C} 3^{i} c_{t}^{g}\right),
\end{aligned}
$$

where $\lambda_{i} \geq 0, m_{1 i}, m_{2 i} \in \mathbb{R}$ with $i, j=1,2$ and $i \neq j$.

Following the same reasoning as in Appendix B, the FOCs become

$$
\begin{gathered}
b\left(\mathbf{Q}^{i \prime}+\mathbf{Q}^{i}+\lambda_{i}\left(\mathbf{Q}^{j \prime}+\mathbf{Q}^{j}\right)\right) \mathbf{u}_{i t}+c_{t}^{g}\left(\mathbf{Q}_{3}^{i \prime}+\lambda_{i} \mathbf{Q}_{3}^{j \prime}\right)+\mathbf{D} 2^{i \prime} m_{1 i}+\mathbf{C} 2^{i \prime} m_{2 i}=0 \\
-2 b\left(\mathbf{R}^{i}+\lambda_{i} \mathbf{R}^{j}\right) \pi_{t}+m_{2 i}=0 \\
\beta \frac{\partial E_{t} C^{i}\left(\mathbf{S}_{t}\right)}{\partial \mathbf{S}_{t}}+\lambda_{i} \beta \frac{\partial E_{t} C^{j}\left(\mathbf{S}_{t}\right)}{\partial \mathbf{S}_{t}}+m_{1 i}=0 \\
\lambda_{i}\left(W^{j}\left(\mathbf{S}_{t-1}\right)-X(1-\delta)-\delta V^{j}\left(\mathbf{S}_{t-1}\right)\right)=0
\end{gathered}
$$

and the constraints $(\mathrm{C} 1)$ and $(\mathrm{C} 2)$. Then, the FOC $(\mathrm{C} 3)$ can be rewritten as follows

$$
\left(\mathbf{E} 1^{i}+\lambda_{i} \mathbf{R} 1^{j}\right) \mathbf{S}_{t-1}+\left(\mathbf{E} 0^{i}+\lambda_{i} \mathbf{R} \mathbf{0}^{j}\right) \mathbf{u}_{i t}+\left(\mathbf{E} 2^{i}+\lambda_{i} \mathbf{R} 2^{j}\right) c_{t}^{g}=0,
$$


with

$$
\begin{aligned}
& \underset{2 x 1}{\mathbf{E} 1^{i}}=2 \mathbf{C} 2^{i \prime} \mathbf{R}^{i} \mathbf{C} 1^{i}+\beta \mathbf{D} 2^{i \prime}\left(\boldsymbol{\beta}^{i}+\beta^{i \prime}\right) \mathbf{D} 1^{i} \\
& \underset{2 x 2}{\mathbf{E} 0^{i}}=2 \mathbf{C} 2^{i \prime} \mathbf{R}^{i} \mathbf{C} 2^{i}+\mathbf{Q}_{2}^{i}+\mathbf{Q}_{2}^{i \prime}+\beta \mathbf{D} 2^{i \prime}\left(\boldsymbol{\beta}^{i}+\boldsymbol{\beta}^{i \prime}\right) \mathbf{D} 2^{i} \\
& \underset{2 x 1}{\mathbf{E} 2^{i}}=2 \mathbf{C} 2^{i \prime} \mathbf{R}^{i} \mathbf{C} 3^{i}+\mathbf{Q}_{3}^{i \prime}+\beta \mathbf{D} 2^{i \prime}\left(\boldsymbol{\beta}^{i}+\boldsymbol{\beta}^{i \prime}\right) \mathbf{D} 3^{i} \\
& \underset{2 x 1}{\mathbf{R}^{j}}=2 \mathbf{R}^{j} \mathbf{C} 2^{i \prime} \mathbf{C} 1^{i}+\beta \mathbf{D} 2^{i \prime}\left(\boldsymbol{\beta}^{j}+\beta^{j \prime}\right) \mathbf{D} 1^{i} \\
& \underset{2 \times 2}{\mathbf{R} 0^{j}}=2 \mathbf{R}^{j} \mathbf{C} 2^{i \prime} \mathbf{C} 2^{i}+\mathbf{Q}_{2}^{j}+\mathbf{Q}_{2}^{j^{\prime}}+\beta \mathbf{D} 2^{i \prime}\left(\boldsymbol{\beta}^{j}+\boldsymbol{\beta}^{j \prime}\right) \mathbf{D} 2^{i} \\
& \underset{2 x 1}{\mathbf{R}{ }^{j}}=2 \mathbf{R}^{j} \mathbf{C} 2^{i \prime} \mathbf{C} 3^{i}+\mathbf{Q}_{3}^{j^{\prime}}+\beta \mathbf{D} 2^{i \prime}\left(\boldsymbol{\beta}^{j}+\boldsymbol{\beta}^{j \prime}\right) \mathbf{D} 3^{i} .
\end{aligned}
$$

Hence, the optimal policy $\mathbf{u}_{i t}$ is the best (bargained) response to CB's control $c_{t}^{g}$,

$$
\mathbf{u}_{i t}=\mathbf{O} 1^{i} \mathbf{S}_{t-1}+\mathbf{O} 2^{i} c_{t}^{g},
$$

where $\mathbf{O 1} 1^{i}=-\left(\mathbf{L} 0^{i}\right)^{-1} \mathbf{L} 1^{i}, \mathbf{O} 2^{i}=-\left(\mathbf{L} 0^{i}\right)^{-1} \mathbf{L} 2^{i}$ with $\mathbf{L} \mathbf{J}^{i}=\mathbf{E} \mathbf{J}^{i}-\lambda_{i} \mathbf{R} \mathbf{J}^{j}$ where $\mathbf{J}=\mathbf{0}, \mathbf{1}, \mathbf{2}$; $i, j=1,2$ and $i \neq j$.

The Central Bank's Problem. The problem for the $\mathrm{CB}$ is simpler since it does not directly involve any negotiation. Its problem (conditional on player $i$ making an acceptable offer) is

$$
\begin{aligned}
L^{i}\left(\mathbf{S}_{t-1}\right)= & V^{C}\left(\mathbf{S}_{t-1}\right)+m_{1 i}\left(\mathbf{S}_{t}-\mathbf{D} 1^{i} \mathbf{S}_{t-1}-\mathbf{D} 2^{i} \mathbf{u}_{i t}-\mathbf{D 3}^{i} c_{t}^{g}\right) \\
& +m_{2 i}\left(\pi_{t}-\mathbf{C} \mathbf{1}^{i} \mathbf{S}_{t-1}-\mathbf{C} 2^{i} \mathbf{u}_{i t}-\mathbf{C} 3^{i} c_{t}^{g}\right),
\end{aligned}
$$

with

$$
\begin{aligned}
V^{C}\left(\mathbf{S}_{t-1}\right)= & A-\min _{c_{t}}\left(b\left(\pi_{t} \mathbf{R}^{C} \pi_{t}+c_{t}^{g} \mathbf{Q}_{1}^{C} c_{t}^{g}+\mathbf{u}_{i t}^{\prime} \mathbf{Q}_{2}^{C} \mathbf{u}_{i t}+c_{t}^{g} \mathbf{Q}_{3}^{C} \mathbf{u}_{i t}\right)\right. \\
& \left.+-\beta E_{t} C^{C}\left(\mathbf{S}_{t}\right)\right) .
\end{aligned}
$$

The matrices $\mathbf{Q}_{z}^{C}$ (and $\mathbf{R}^{C}$ ) are defined as $\mathbf{Q}_{z}^{i}$ (and $\mathbf{R}^{i}$, respectively) with $x_{i}^{g}=x_{i}^{c}=x_{i}^{y}=1$ with $z=1,2,3$. Hence, CB and political parties have exactly the same matrices $\mathbf{Q}_{z}^{C}=\mathbf{Q}_{z}^{i}$ for $z=1,3$, since these are independent of the weights given to public spending and inflation. Let $\boldsymbol{\Phi}_{i}^{C}$ be the guessed parameters for the CB's value function when political party $i$ is in power

$$
V^{C}\left(\mathbf{S}_{t-1}\right)=A-b \mathbf{S}_{t-1}^{\prime} \boldsymbol{\Phi}_{i}^{C} \mathbf{S}_{t-1}
$$

Then, given that $i$ will proposed with probability $q^{i}$ next (when the state is $\mathbf{S}_{t}$ ), the value of the continuation game is

$$
\begin{aligned}
E_{t} C^{C}\left(\mathbf{S}_{t}\right) & =q^{i} V^{C}\left(\mathbf{S}_{t} \mid i\right)+\left(1-q^{i}\right) V^{C}\left(\mathbf{S}_{t} \mid j\right) \\
& =A-b \mathbf{S}_{t-1} \boldsymbol{\beta}^{C} \mathbf{S}_{t-1}
\end{aligned}
$$

with

$$
\boldsymbol{\beta}^{C}=q^{i} \boldsymbol{\Phi}_{i}^{C}+\left(1-q^{i}\right) \boldsymbol{\Phi}_{j}^{C}
$$


The FOCs with respect to $c_{t}^{g}, \pi_{t}, \mathbf{S}_{t}$ and the multipliers are

$$
\begin{aligned}
b\left(2 \mathbf{Q}_{1}^{C} c_{t}^{g}+\mathbf{Q}_{3}^{C} \mathbf{u}_{i t}\right)+\mathbf{D 3}^{i} m_{1 i}+\mathbf{C 3}^{i} m_{2 i} & =0 \\
-2 b \mathbf{R}^{C} \pi_{t}+m_{2 i} & =0 \\
-\beta b\left(\boldsymbol{\beta}^{C}+\boldsymbol{\beta}^{C \prime}\right) \mathbf{S}_{t}+m_{1 i} & =0,
\end{aligned}
$$

and the constraints $(\mathrm{C} 1)$ and $(\mathrm{C} 2)$. Then, FOC $(\mathrm{C} 10)$ can be rewritten as follows

$$
\begin{gathered}
\mathbf{E} \mathbf{1}_{C}^{i} \mathbf{S}_{t-1}+\mathbf{E} \mathbf{0}_{C}^{i} \mathbf{u}_{i t}+\mathbf{E} 2_{C}^{i} c_{t}^{g}=0 \\
\mathbf{E} \mathbf{1}_{C}^{i}=2 \mathbf{C} 3^{i} \mathbf{R}^{C} \mathbf{C} 1^{i}+\beta \mathbf{D 3}^{i}\left(\boldsymbol{\beta}^{C}+\boldsymbol{\beta}^{C \prime}\right) \mathbf{D} 1^{i} \\
\mathbf{E} \mathbf{0}_{C}^{i}=2 \mathbf{C} 3^{i} \mathbf{R}^{C} \mathbf{C} 2^{i}+\mathbf{Q}_{3}^{C}+\beta \mathbf{D} 3^{i}\left(\boldsymbol{\beta}^{C}+\boldsymbol{\beta}^{C \prime}\right) \mathbf{D} 2^{i} \\
\mathbf{E} 2_{C}^{i}=2 \mathbf{C} 3^{i} \mathbf{R}^{C} \mathbf{C} 3^{i}+2 \mathbf{Q}_{1}^{C}+\beta \mathbf{D} 3^{i}\left(\boldsymbol{\beta}^{C}+\boldsymbol{\beta}^{C \prime}\right) \mathbf{D} 3^{i} .
\end{gathered}
$$

Then, the optimal control for CB is the best response to the political parties' agreed policy $\mathbf{u}_{i t}$ and a function of the state $\mathbf{S}_{t-1}$

$$
c_{t}^{g}=\mathbf{O} 1_{C}^{i} \mathbf{S}_{t-1}+\mathbf{O} 2_{C}^{i} \mathbf{u}_{i t},
$$

with

$$
\begin{aligned}
& \mathbf{O 1} 1_{C}^{i}=-\left(\mathbf{E} 2_{C}^{i}\right)^{-1} \mathbf{E} 1_{C}^{i}, \\
& \mathbf{O} 2_{C}^{i}=-\left(\mathbf{E} 2_{C}^{i}\right)^{-1} \mathbf{E} \mathbf{0}_{C}^{i} .
\end{aligned}
$$

The Solution. Next, we solve the two best responses in (C8) and (C13), simultaneously, to obtain

$$
\begin{aligned}
\mathbf{u}_{i t} & =\mathbf{O 1}_{B}^{i} \mathbf{S}_{t-1} \\
c_{t}^{g} & =\mathbf{O 1}_{C B}^{i} \mathbf{S}_{t-1},
\end{aligned}
$$

where

$$
\begin{aligned}
\mathbf{O 1} 1_{B}^{i} & =\left[\mathbf{I}-\mathbf{O} 2^{i} \mathbf{O} 2_{C}^{i}\right]^{-1}\left(\mathbf{O 1}{ }^{i}+\mathbf{O 2}^{i} \mathbf{O} 1_{C}^{i}\right), \\
\mathbf{O 1}_{C B}^{i} & =\mathbf{O} 1_{C}^{i}+\mathbf{O 2}_{C}^{i} \mathbf{O 1}_{B}^{i} .
\end{aligned}
$$

Then, using the optimal controls (C14) and (C15), the inflation rate, in equilibrium, is given by:

$$
\pi_{t}=\mathbf{P} \mathbf{0}_{C B}^{i} \mathbf{S}_{t-1},
$$

where

$$
\mathbf{P 0}{ }_{C B}^{i}=\mathbf{C 1}{ }^{i}+\mathbf{C 2}^{i} \mathbf{O 1}_{B}^{i}+\mathbf{C 3}^{i} \mathbf{O 1}_{C B}^{i} .
$$

Similarly, for the equation of motion $(\mathrm{C} 1)$ :

$$
\mathbf{S}_{t}=\mathbf{G i}_{C B}^{i} \mathbf{S}_{t-1},
$$

with

$$
\mathbf{G} \mathbf{1}_{C B}^{i}=\mathbf{D} 1^{i}+\mathbf{D} 2^{i} \mathbf{O 1}{ }_{B}^{i}+\mathbf{D 3}^{i} \mathbf{O 1}_{C B}^{i} .
$$

The guessed coefficients in the forecasts are also linear:

$$
E_{t}\left(\pi_{t+1}\right)=\left(q^{i} \mathbf{P} \mathbf{0}_{C B}^{i}+\left(1-q^{i}\right) \mathbf{P} \mathbf{0}_{C B}^{j}\right) \mathbf{S}_{t},
$$


with

$$
f=q^{i} \mathbf{P} \mathbf{0}_{C B}^{i}+\left(1-q^{i}\right) \mathbf{P 0}_{C B}^{j},
$$

and

$$
E_{t}\left(c_{t+1}^{g}\right)=\left(q^{i} \mathbf{O} \mathbf{1}_{C B}^{i}+\left(1-q^{i}\right) \mathbf{O} \mathbf{1}_{C B}^{j}\right) \mathbf{S}_{t},
$$

with

$$
c=q^{i} \mathbf{O} 1_{C B}^{i}+\left(1-q^{i}\right) \mathbf{O} 1_{C B}^{j} .
$$

The guessed coefficients in the forecasts ( $c$ and $f$ ) are the same for the two political parties and CB. Finally, the guessed coefficients for the payoffs are as follows:

$$
\begin{aligned}
& \boldsymbol{\Phi}^{i}=\mathbf{P} \mathbf{0}_{C B}^{i^{\prime}} \mathbf{R}^{i} \mathbf{P} \mathbf{0}_{C B}^{i}+\mathbf{O} 1_{C B}^{i} \mathbf{Q}_{1}^{i} \mathbf{O} 1_{C B}^{i}+\mathbf{O} 1_{B}^{i \prime} \mathbf{Q}_{2}^{i} \mathbf{O} 1_{B}^{i}
\end{aligned}
$$

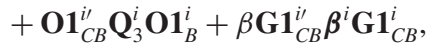

$$
\begin{aligned}
& \boldsymbol{\mu}^{j}=\mathbf{P} \mathbf{0}_{C B}^{i^{\prime}} \mathbf{R}^{j} \mathbf{P} \mathbf{0}_{C B}^{i}+\mathbf{O} 1_{C B}^{i \prime} \mathbf{Q}_{1}^{j} \mathbf{O} 1_{C B}^{i}+\mathbf{O} 1_{B}^{i \prime} \mathbf{Q}_{2}^{j} \mathbf{O} 1_{B}^{i} \\
& +\mathbf{O 1}_{C B}^{i \prime} \mathbf{Q}_{3}^{j} \mathbf{O 1}{ }_{B}^{i}+\beta \mathbf{G 1}_{C B}^{i \prime} \boldsymbol{\beta}^{j} \mathbf{G} \mathbf{1}_{C B}^{i} \text {, } \\
& \boldsymbol{\Phi}_{\mathbf{i}}^{C B}=\mathbf{P} \mathbf{0}_{C B}^{i^{\prime}} \mathbf{R}^{C} \mathbf{P} \mathbf{0}_{C B}^{i}+\mathbf{O} \mathbf{1}_{C B}^{i \prime} \mathbf{Q}_{1}^{C} \mathbf{O} \mathbf{1}_{C B}^{i}+\mathbf{O} \mathbf{1}_{B}^{i \prime} \mathbf{Q}_{2}^{C} \mathbf{O} \mathbf{1}_{B}^{i} \\
& +\mathbf{O 1}{ }_{C B}^{i \prime} \mathbf{Q}_{3}^{C} \mathbf{O} \mathbf{1}_{B}^{i}+\beta \mathbf{G} \mathbf{1}_{C B}^{i \prime} \boldsymbol{\beta}^{C} \mathbf{G} \mathbf{1}_{C B}^{i} \text {. }
\end{aligned}
$$

The MPE is, then, given by solving the set of equations in $\boldsymbol{\Phi}^{i}, \boldsymbol{\mu}^{i}$ and $\boldsymbol{\Phi}_{\mathbf{i}}^{C B}$ in (C22)-(C24) together with, first,

$$
\boldsymbol{\beta}^{i}=q^{i} \boldsymbol{\Phi}^{i}+\left(1-q^{i}\right) \boldsymbol{\mu}^{i},
$$

second, the equivalent for $\mathrm{CB}, \boldsymbol{\beta}^{C}$ in (C9) and, third, the acceptance condition as in (B4), which for $D=(1-\delta) X$, and for $\lambda_{i}>0$ is

$$
\boldsymbol{\mu}^{j}=\delta \boldsymbol{\Phi}^{j},
$$

for $i, j=1,2$ and $i \neq j$.

\section{APPENDIX D: NON-SEPARABILITY OF PUBLIC AND PRIVATE CONSUMPTION}

(1) Changes to the Model As a result of introducing non-separable utility, the loglinearized version of the consumption Euler equation (5) can be written as

$$
\widehat{\widetilde{C}}_{t}+\widehat{\xi}_{t}=E_{t}\left(\widehat{\widetilde{C}}_{t+1}+\widehat{\xi}_{t+1}\right)-\frac{1}{\sigma}\left(r_{t}-E_{t}\left(\pi_{t+1}\right)\right)
$$

where $\widetilde{C}_{t}=C_{t}+v G_{t}$ such that $v<(>) 0$ implies private and public consumption are complements (substitutes), hatted variables denote percentage deviations from steady state, $r_{t}=R_{t}-\rho$ where $\rho=\frac{1}{\beta}-1$, and $\pi_{t}=p_{t}-p_{t-1}$ is price inflation.

Similarly, the households' labor supply decision and is given by

$$
-\frac{\bar{\tau}}{1-\bar{\tau}} \widehat{\tau}_{t}+\widehat{w}_{t}=\varphi \widehat{N}_{t}+\sigma \widehat{\widetilde{C}}_{t}+\widehat{\xi}_{t}^{N}
$$


Market clearing is as before, but can be written in terms of the adjusted consumption variable, $\widetilde{C}_{t}$, before being log-linearized as

$$
\widehat{Y}_{t}=\theta^{\prime} \widehat{\widetilde{C}}_{t}+\left(1-\theta^{\prime}\right) \widehat{G}_{t},
$$

where we now define $\theta^{\prime}=\frac{\overline{\widetilde{C}}}{\bar{Y}}$ and $1-\theta^{\prime}=(1-v) \frac{\bar{G}}{\bar{Y}}$.

The budget constraint is linearized as,

$$
\begin{aligned}
\widehat{b}_{t-1}-\pi_{t}= & \beta\left[\widehat{b}_{t}-E_{t}\left\{\pi_{t+1}+\sigma\left(\widehat{\widetilde{C}}_{t+1}+\widehat{\xi}_{t+1}\right)\right\}\right] \\
& +\sigma \beta\left(\widehat{\widetilde{C}}_{t}+\widehat{\xi}_{t}\right)+\frac{\bar{w} \bar{N} \bar{\tau}}{\bar{b}}\left(\widehat{w}_{t}+\widehat{N}_{t}+\widehat{\tau}_{t}\right)-\frac{\bar{G}}{\bar{b}} \widehat{G}_{t},
\end{aligned}
$$

and the NKPC becomes

$$
\pi_{t}=\beta E_{t} \pi_{t+1}+\gamma\left(\widehat{m c}_{t}+\widehat{\mu}_{t}\right)
$$

where $\gamma=\frac{\left(1-\theta_{p} \beta\right)\left(1-\theta_{p}\right)}{\theta_{p}}, \widehat{m c}_{t}=-a_{t}+\widehat{w}_{t}=\varphi \widehat{N}_{t}+\sigma \widehat{\widetilde{C}}_{t}+\widehat{\xi}_{t}^{N}+\frac{\bar{\tau}}{1-\bar{\tau}} \widehat{\tau}_{t}-a_{t}$, are the real loglinearized marginal costs of production, and $\widehat{\mu}$ is a mark-up shock representing the temporary deviation of the desired markup from its steady-state value.

As a result, the model is essentially unchanged except for the redefinition of the consumption variable to account for the impact of public consumption on household utility from private consumption and the resultant reinterpretation of parameter $\theta^{\prime}$. However, we need to re-derive the policy problem to ensure this is also amended appropriately as a result of this change to household preferences. To do so we initially consider the social planner's problem, map that solution to the flexible price equilibrium, rewrite the model in gap form, and then construct a measure of social welfare.

(2) Social Planner's Problem The social planner is not constrained by the price mechanism and simply maximizes the representative household's utility, (55), subject to the technology, (7), and resource constraints, (9). This yields the following FOCs:

$$
\begin{gathered}
\left(\widetilde{C}_{t}^{*}\right)^{-\sigma}=\frac{\chi}{1-v}\left(G_{t}^{*}\right)^{-\sigma} \\
\left(\widetilde{C}_{t}^{*}\right)^{-\sigma}-Y_{t}^{* \varphi} A_{t}^{-(1+\varphi)} \xi_{t}^{N}=0,
\end{gathered}
$$

where we retain use of the "*” superscript to denote the efficient level of that variable. These can be log-linearized around the efficient steady state and given the national accounting identity we obtain

$$
\widehat{Y}_{t}^{*}=\left(\frac{1+\varphi}{\sigma+\varphi}\right) a_{t}-\frac{1}{\sigma+\varphi} \widehat{\xi}_{t}^{N}
$$

and,

$$
\widehat{Y}_{t}^{*}=\widehat{\widetilde{C}}_{t}^{*}=\widehat{G}_{t}^{*}
$$

Therefore, the social planner takes account of the impact of public goods provision on the utility obtained from private consumption in setting the balance between private and public consumption. 
(3) Flexible Price Equilibrium Profit-maximizing behavior implies that firms will operate at the point at which marginal costs equal marginal revenues

$$
\begin{aligned}
-\ln \left(\mu_{t}\right) & =m c_{t} \\
\left(1-\frac{1}{\epsilon}\right) & =\frac{(1-\varkappa)}{\left(1-\tau_{t}\right)}\left(N_{t}^{n}\right)^{\varphi} A_{t}^{-1}\left(\widetilde{C}_{t}^{n}\right)^{\sigma} \xi_{t}^{N} .
\end{aligned}
$$

In the steady state, this reduces to

$$
\left(1-\frac{1}{\bar{\epsilon}}\right)=\frac{(1-\varkappa)}{(1-\bar{\tau})}\left(\bar{N}^{n}\right)^{\varphi}\left(\overline{\widetilde{C}}^{n}\right)^{\sigma} .
$$

If the subsidy $\varkappa$ is given by

$$
(1-\varkappa)=\left(1-\frac{1}{\bar{\epsilon}}\right)(1-\bar{\tau})
$$

then

$$
\left(\widetilde{\widetilde{C}}^{n}\right)^{-\sigma}=\left(\bar{N}^{n}\right)^{\varphi}
$$

which is identical to the optimal level of employment in the efficient steady state. Given the steady-state government spending rule

$$
\frac{\bar{G}}{\bar{Y}}=\left(1-v+\left(\frac{\chi}{1-v}\right)^{-\frac{1}{\sigma}}\right)^{-1},
$$

the steady-state level of output is given by

$$
\bar{Y}=\bar{N}=\left(1+(1-v)^{\frac{\sigma-1}{\sigma}} \chi^{\frac{1}{\sigma}}\right)^{\frac{\sigma}{\sigma+\varphi}},
$$

and, if the subsidy is in place, then the steady-state real wage is given by

$$
\bar{w}=\frac{1}{1-\bar{\tau}} .
$$

The steady-state tax rate required to support a given debt-GDP ratio is given by

$$
\bar{\tau}=\frac{(1-\beta) \frac{\bar{B}}{\bar{Y}}+\frac{\bar{G}}{\bar{Y}}}{1+(1-\beta) \frac{\bar{B}}{\bar{Y}}+\frac{\bar{G}}{\bar{Y}}},
$$

and the tax revenues relative to debt are given by

$$
\frac{\bar{w} \bar{N} \bar{\tau}}{\bar{b}}=\frac{\frac{\bar{\tau}}{1-\bar{\tau}}}{\frac{\bar{B}}{\bar{Y}}} .
$$

This is sufficient to define all log-linearized relationships dependent on model parameters and the debt-GDP ratio. Therefore, the same form of subsidy in combination with a government spending rule which takes account of the impact of public consumption on private utility ensures the steady state of our sticky price economy is efficient. This enables us to rewrite the model in a gap form which is isomorphic to the original model with $c_{t}^{v}=\widehat{\widetilde{C}}_{t}-\widehat{\widetilde{C}}_{t}^{*}$ which replaces $c_{t}^{g}=\widehat{C}_{t}-\widehat{C}_{t}^{*}$ and $\theta=\frac{\widetilde{C}}{\bar{Y}}$ rather than $\frac{\bar{C}}{\bar{Y}}$. 
(4) Social Welfare Using the results above, the term in adjusted consumption can be approximated to a second order as

$$
\frac{\widetilde{C}_{t}^{1-\sigma} \xi_{t}^{-\sigma}}{1-\sigma}=\widetilde{\widetilde{C}}^{1-\sigma}\left(\widehat{\widetilde{C}}_{t}+\frac{1}{2}(1-\sigma) \widehat{\widetilde{C}}_{t}^{2}-\sigma \widehat{\widetilde{C}}_{t} \widehat{\xi}_{t}\right)+t i p+O[2]
$$

Similarly for the separable term in government spending

$$
\chi \frac{G_{t}^{1-\sigma} \xi_{t}^{-\sigma}}{1-\sigma}=\chi \bar{G}^{1-\sigma}\left(\widehat{G}_{t}+\frac{1}{2}(1-\sigma) \widehat{G}_{t}^{2}-\sigma \widehat{G}_{t} \widehat{\xi}_{t}\right)+t i p+O[2] .
$$

The final term in labor supply can be written as

$$
\frac{N_{t}^{1+\varphi} \xi_{t}^{N} \xi_{t}^{-\sigma}}{1+\varphi}=\bar{N}^{1+\varphi}\left(\widehat{N}_{t}+\frac{1}{2}(1+\varphi) \widehat{N}_{t}^{2}-\sigma \widehat{N}_{t} \widehat{\xi}_{t}+\widehat{N}_{t} \widehat{\xi}_{t}^{N}\right)+t i p+O[2]
$$

These can be combined as

$$
\begin{aligned}
\Gamma_{t}= & \widetilde{\widetilde{C}}^{1-\sigma}\left(\widehat{\widetilde{C}}_{t}+\frac{1}{2}(1-\sigma) \widehat{\vec{C}}_{t}^{2}-\sigma \widehat{\widetilde{C}}_{t} \widehat{\xi}_{t}\right) \\
& +\chi \bar{G}^{1-\sigma}\left(\widehat{G}_{t}+\frac{1}{2}(1-\sigma) \widehat{G}_{t}^{2}-\sigma \widehat{G}_{t} \widehat{\xi}_{t}\right) \\
& -\bar{N}^{1+\varphi}\left(\widehat{Y}_{t}+\frac{1}{2}(1+\varphi) \widehat{Y}_{t}^{2}-(1+\varphi) \widehat{Y}_{t} a_{t}\right. \\
& \left.-\sigma \widehat{Y}_{t} \widehat{\xi}_{t}+\widehat{Y}_{t} \widehat{\xi}_{t}^{N}+\frac{\epsilon}{2} \operatorname{var}_{i}\left(p_{t}(i)\right)\right) \\
& +\operatorname{tip}+O[2] .
\end{aligned}
$$

Using second-order approximation to the national accounting identity

$$
\theta^{\prime} \widehat{\widetilde{C}}_{t}=\widehat{Y}_{t}-\left(1-\theta^{\prime}\right) \widehat{G}_{t}-\frac{1}{2} \theta^{\prime} \widehat{\widetilde{C}}_{t}^{2}-\frac{1}{2}\left(1-\theta^{\prime}\right) \widehat{G}_{t}^{2}+\frac{1}{2} \widehat{Y}_{t}^{2}+O[2] .
$$

With the steady-state subsidy in place and government spending chosen optimally, the following conditions hold in the steady state

$$
\bar{C}^{1-\sigma}=\bar{N}^{1+\varphi} \theta^{\prime}
$$

and

$$
\chi \bar{G}^{1-\sigma}=\bar{N}^{1+\varphi}\left(1-\theta^{\prime}\right),
$$

which allows us to eliminate the levels terms and rewrite welfare as

$$
\begin{aligned}
\Gamma_{t}= & \widetilde{C}^{1-\sigma}\left\{-\frac{1}{2} \sigma \widehat{\widetilde{C}}_{t}^{2}-\sigma \widehat{\widetilde{C}}_{t} \widehat{\xi}_{t}\right\}+\chi \bar{G}^{1-\sigma}\left\{-\frac{1}{2} \sigma \widehat{G}_{t}^{2}-\sigma \widehat{G}_{t} \widehat{\xi}_{t}\right\} \\
& -\bar{N}^{1+\varphi}\left\{\frac{1}{2} \varphi \widehat{Y}_{t}^{2}-(1+\varphi) \widehat{Y}_{t} a_{t}-\sigma \widehat{Y}_{t} \widehat{\xi}_{t}+\widehat{Y}_{t} \widehat{\xi}_{t}^{N}+\frac{\epsilon}{2} \operatorname{var}_{i}\left\{p_{t}(i)\right\}\right\} \\
& +t i p+O[2] .
\end{aligned}
$$


We now need to rewrite this in gap form using the FOCs for the social planner to eliminate the term in the technology shock

$$
\begin{aligned}
\Gamma_{t}= & -\bar{N}^{1+\varphi} \frac{1}{2}\left[\sigma \theta^{\prime}\left(\widehat{\widetilde{C}}_{t}-\widehat{\widetilde{C}}_{t}^{*}\right)^{2}+\sigma\left(1-\theta^{\prime}\right)\left(\widehat{G}_{t}-\widehat{G}_{t}^{*}\right)^{2}+\varphi\left(\widehat{Y}_{t}-\widehat{Y}_{t}^{*}\right)^{2}+\epsilon \operatorname{var}_{i}\left(p_{t}(i)\right)\right] \\
& +\operatorname{tip}+O[2] .
\end{aligned}
$$

Using the result from Woodford (2003) that

$$
\sum_{t=0}^{\infty} \beta^{t} \operatorname{var}_{i}\left(p_{t}(i)\right)=\frac{\theta^{\prime}}{\left(1-\theta^{\prime}\right)\left(1-\theta^{\prime} \beta\right)} \sum_{t=0}^{\infty} \beta^{t} \pi_{t}^{2}+t i p+O[2],
$$

we can write the discounted sum of utility as

$$
\begin{aligned}
\Gamma= & -\bar{N}^{1+\varphi} \frac{1}{2} E_{0} \sum_{t=0}^{\infty} \beta^{t}\left[\sigma \theta^{\prime}\left(\widehat{\widetilde{C}}_{t}-\widehat{\widetilde{C}}_{t}^{*}\right)^{2}+\sigma\left(1-\theta^{\prime}\right)\left(\widehat{G}_{t}-\widehat{G}_{t}^{*}\right)^{2}+\varphi\left(\widehat{Y}_{t}-\widehat{Y}_{t}^{*}\right)^{2}+\frac{\epsilon}{\gamma} \pi_{t}^{2}\right] \\
& + \text { tip }+O[2] .
\end{aligned}
$$

In other words, the problem is isomorphic to the original problem but with private consumption, $c_{t}^{g}$, replaced with private consumption adjusted for the impact of government spending, $c_{t}^{v}$, and the parameter $\theta$ replaced by $\theta^{\prime}=\frac{\widetilde{\widetilde{C}}}{\bar{Y}}$. 